Interfacial shear in adiabatic downward gas/liquid co-current annular flow in pipes, Experimental Thermal and Fluid Science, Volume 72, April 2016, Pages 75-87. DOI: 10.1016/j.expthermflusci.2015.10.025

Experimental Thermal and Fluid Science

$$
\text { Elsevier Editorial system(tm) for }
$$

Manuscript Draft

Manuscript Number: ETFS-D-15-00429R1

Title: Interfacial shear in adiabatic downward gas/liquid co-current annular flow in pipes

Article Type: Research Paper

Keywords: Annular flow, interfacial friction factor, interfacial shear stress, multiphase flow, pressure gradient, vertical downward flow

Corresponding Author: Mr. Aliyu Musa Aliyu, MSc

Corresponding Author's Institution: Cranfield University

First Author: Aliyu Musa Aliyu, MSc

Order of Authors: Aliyu Musa Aliyu, MSc; Liyun Lao, PhD; Almabrok A Almabrok, PhD; Hoi Yeung, PhD

Abstract: Interfacial friction is one of the key variables for predicting annular two-phase flow behaviours in vertical pipes. In order to develop an improved correlation for interfacial friction factor in downward cocurrent annular flow, the pressure gradient, film thickness and film velocity data were generated from experiments carried out on Cranfield University's Serpent Rig, an air/water two-phase vertical flow loop of $101.6 \mathrm{~mm}$ internal diameter. The air and water superficial velocity ranges used are 1.42-28.87 and 0.1-1.0 m/s respectively. These correspond to Reynolds number values of 8400-187000 and 11000-113000 respectively. The correlation takes into account the effect of pipe diameter by using the interfacial shear data together with dimensionless liquid film thicknesses related to different pipe sizes ranging from 10 to $101.6 \mathrm{~mm}$, including those from published sources by numerous investigators. It is shown that the predictions of this new correlation outperform those from previously reported studies.

Published by Elsevier. This is the Author Accepted Manuscript issued with:

Creative Commons Attribution Non-Commercial No Derivatives License (CC:BY:NC:ND 3.0).

The final published version (version of record) is available online at 10.1016/j.expthermflusci.2015.10.025

Please refer to any applicable publisher terms of use. 


\title{
Interfacial shear in adiabatic downward gas/liquid co- current annular flow in pipes
}

\author{
Aliyu M. Aliyu ${ }^{1}$, Liyun Lao ${ }^{1}$, Almabrok A. Almabrok ${ }^{2}$, Hoi Yeung $^{1}$ \\ ${ }^{1}$ Oil and Gas Engineering Centre, School of Energy, Environment and Agrifood, Cranfield University, \\ Bedfordshire MK43 0AL, United Kingdom \\ ${ }^{2}$ Department of Petroleum Engineering, Faculty of Engineering, Sirte University, Libya
}

\begin{abstract}
Interfacial friction is one of the key variables for predicting annular two-phase flow behaviours in vertical pipes. In order to develop an improved correlation for interfacial friction factor in downward co-current annular flow, the pressure gradient, film thickness and film velocity data were generated from experiments carried out on Cranfield University's Serpent Rig, an air/water twophase vertical flow loop of $101.6 \mathrm{~mm}$ internal diameter. The air and water superficial velocity ranges used are $1.42-28.87$ and $0.1-1.0 \mathrm{~m} / \mathrm{s}$ respectively. These correspond to Reynolds number values of 8400-187000 and 11000-113000 respectively. The correlation takes into account the effect of pipe diameter by using the interfacial shear data together with dimensionless liquid film thicknesses related to different pipe sizes ranging from 10 to $101.6 \mathrm{~mm}$, including those from published sources by numerous investigators. It is shown that the predictions of this new correlation outperform those from previously reported studies.
\end{abstract}

Keywords: Annular flow, interfacial friction factor, interfacial shear stress, multiphase flow, pressure gradient, vertical downward flow

\section{Introduction}

A large number of studies have been carried out on vertical air-water two-phase annular flow in pipes. This is not surprising considering the huge importance annular two-phase flow plays in the nuclear, chemical and petroleum industries where it is generally agreed to be one of the most frequently encountered flow patterns. To this end, many studies have been commissioned to investigate annular two-phase flow phenomena with the bulk of published works focussing on cocurrent upward annular flow. In sharp contrast there have been far fewer studies published on cocurrent downward annular two-phase flows. This is against the backdrop that co-current downward annular two-phase flow is also often encountered in engineering equipment such as gas absorbers as falling film flow, gas condensate pipelines, refrigeration systems, and in heat transfer equipment like boilers and heat exchangers. What little work is available is dominated by pipes of which the scales are much less than $100 \mathrm{~mm}$ in internal diameter. It has been noted that there is no guarantee that the use of models developed for these small pipes will predict large diameter flows well; therefore several reported studies (Oliemans et al. 1985; Kataoka \& Ishii 1987; Omebere-Iyari 2006; Omebere-Iyari \& Azzopardi 2007; Kaji \& Azzopardi 2010; Peng et al. 2010; Lao et al. 2012; Schlegel et al. 2012) have addressed that there is need to expand the knowledge of multiphase flow behaviour to large diameter pipe systems. For example, Oliemans et al. (1985) compared entrainment correlations with large diameter test data and concluded there is not much confidence in the predictive value of the correlations. Kataoka \& Ishii (1987) showed that the application of the conventional drift flux model 
for pool void fraction prediction to relatively large vessels was only limited to low gas fluxes, and thus had to develop a new correlation for such large systems when annular flow for instance occurs at higher gas fluxes. Disturbance waves which greatly contribute to wall shear stress and are a source of entrained droplets were observed by Azzopardi et al. (1982) to be incoherent in large diameter pipes. Careful observations revealed that in large pipes, the waves were not perpendicular to the flow direction but were curved "bow waves". This is in sharp contrast to what is obtained in smaller tubes where the waves are continuous around the tube circumference. The study by Omebere-Iyari \& Azzopardi (2007) on disturbance wave velocity provided yet strong quantitative indication of pipe diameter effect on the gas-liquid interface behaviour. They established that Pearce's coeffecient, which is proportional to wave velocity, increases with pipe diameter such that its value of 0.9 remains fairly constant at large pipe diameters.

The interfacial friction factor has been likened to surface roughness in single-phase fluid flow (Bergelin et al., 1949; Wallis, 1969; Hewitt \& Hall-Taylor, 1970). In addition to the wall or skin friction in two-phase flow, interfacial friction as a result of slip between the two phases contributes to the frictional pressure loss. Therefore, the contribution of interfacial friction to the two-phase frictional component increases with increasing slip velocity or as the flow pattern moves from bubbly to annular flow. Klausner et al. (1991) pointed out that the correlations of Henstock \& Hanratty (1976); Andreussi \& Zanelli (1978); and Asali et al. (1985) are the only reported works that proposed relations for determining the downwards interfacial friction factor. Since then, Hajiloo et al. (2001) and Dalkilic et al. (2008) have developed downflow two-phase friction factor correlations, of which the former correlated data obtained from four different tube diameters ranging from 15.6-41.2 mm. The latter used data obtained for refrigerant HFC-134a in an $8.1 \mathrm{~mm}$ diameter vertical tube-in-tube heat exchanger and correlated the two-phase friction factor with an equivalent Reynolds number obtained as a function of gas quality and fluid density ratios. The physical correlating parameters used by Hajiloo et al. (2001) using the friction length parameter and gas Reynolds number are similar to that earlier used by Asali et al. (1985). This method will further be extended in the present work using data obtained from a $101.6 \mathrm{~mm}$ large internal diameter pipe and it is envisaged to improve interfacial friction factor predictions for co-current downward air-water annular flow in large vertical pipelines.

\section{Previous studies on downward two-phase interfacial friction factor empirical modelling}

A number of empirical friction factor correlations have been put forward by prior investigators. Literature is replete with such correlations proposed for upward gas-liquid flow; however, some recommendations have been made for downward gas-liquid flow systems. The fluid combination used in most cases is air and water. Early downward co-current two-phase friction factor correlations were obtained by Chien \& Ibele (1964) and Fedotkin et al. (1979). Hajiloo et al. (2001) noted that the results of the former study show appreciable qualitative agreement of the liquid and gas flow rates such that for a certain pipe diameter, the friction factor, $f$, always increases with increasing liquid flow rate but at some point, there is a decrease with increasing gas flow rate. This is also true when the friction data of Bergelin et al. (1949), Chung \& Mills (1974), and Tishkoff et al. (1979) is plotted against $R e_{g}$ the superficial gas Reynolds number. The correlation of Fedotkin et al. (1979) is not consistent with the others as it shows progressive decrease in the magnitude of $f$ with increasing $R e_{g}$. Conversely, there is generally poor quantitative agreement between these studies. It might be partly due to that the different tube sizes used by each set of investigators greatly affected any agreement. 
Table 1: Summary of previous experimental research on downward co-current interfacial friction factor (All test fluids are air/water at near atmospheric system pressures except where stated)

\begin{tabular}{|c|c|c|c|c|c|}
\hline Reference & $\begin{array}{l}\text { Pipe } \\
\text { diameter } \\
(\mathbf{m m})\end{array}$ & $R e_{g}$ range & $R e_{l}$ range & $\begin{array}{l}\text { Length to } \\
\text { diameter } \\
\text { ratio } \\
\end{array}$ & $\begin{array}{l}\text { Measurement } \\
\text { made }\end{array}$ \\
\hline Bergelin et al. (1949) & 25.4 & $3100-65000$ & $0-10,000$ & 130 & $\Delta P$ \\
\hline Chien \& Ibele (1964) & 50.8 & $28000-350000$ & $1250-22000$ & 63 & $\Delta P, \mathrm{t}^{*}$ \\
\hline Ueda \& Tanaka (1974) & 28.8 & $185-13500$ & $6,000-100000$ & 63 & $\Delta P$ \\
\hline Tishkoff et al. (1979) & 28.6 & $15800-86400$ & $4040-18600$ & 64 & $\Delta P, \mathrm{t}$ \\
\hline $\begin{array}{l}\text { Chung \& Mills } \\
(1974)^{* *}\end{array}$ & 20.5 & $8000-30000$ & $0-8030$ & 77 & $\Delta P$ \\
\hline Fedotkin et al. (1979) & 30 & $6000-30000$ & $2000-30000$ & 79 & $\Delta P, \mathrm{t}$ \\
\hline $\begin{array}{l}\text { Henstock \& Hanratty } \\
(1976)^{+}\end{array}$ & $\begin{array}{l}25.4,50.8 \\
63.5\end{array}$ & $5000-255000$ & $20-15,100$ & $\mathrm{n} / \mathrm{a}$ & $\Delta P, \mathrm{t}, E$ \\
\hline Asali et al. (1985) ${ }^{+}$ & $22.9,42$ & $\mathrm{n} / \mathrm{a}$ & $20-3000$ & $41-75$ & $\Delta P, \mathrm{t}$ \\
\hline Fukano et al. (1991) & $10,16,26$ & $12780-99217$ & $70-2900$ & $269-700$ & $\Delta P, H_{l} *$ \\
\hline Hajiloo et al. (2001) & $\begin{array}{l}15.6,20.3, \\
34.2,41.2\end{array}$ & $3400-21600$ & $5100-27200$ & $43-80$ & $\Delta P$ \\
\hline Present & 101.6 & $8400-187000$ & $11300-113300$ & 46 & $\Delta P, \mathrm{t}$ \\
\hline
\end{tabular}

The correlations found to date factored in the effect of pipe diameter, however, as will be shown later, they do not provide satisfactory enough predictions for pipes of $100 \mathrm{~mm}$ and over - the so-called large diameter pipes. Table 1summarises previous studies of $f$ with the tube diameters given together with the fluid velocity and Reynolds number ranges.

\section{Experimental data from a large diameter flow loop}

\subsection{Description of flow loop}

The two-phase Serpent flow loop in the Oil and Gas Engineering Laboratory of Cranfield University is a specially-built test facility used in the study of flow behaviour around upward and downward pipes joined by U-bends. A schematic of this test apparatus is shown in Figure 1. It is divided into three main parts: the fluid (air and water) supply and metering area, the test area, and the separation section. The flow rig receives measured rates of water and air from the flow metering area to the test rig and finally into the ventilation tank where the air and water are separated. The water is returned back to the storage tank while the air is vented. 


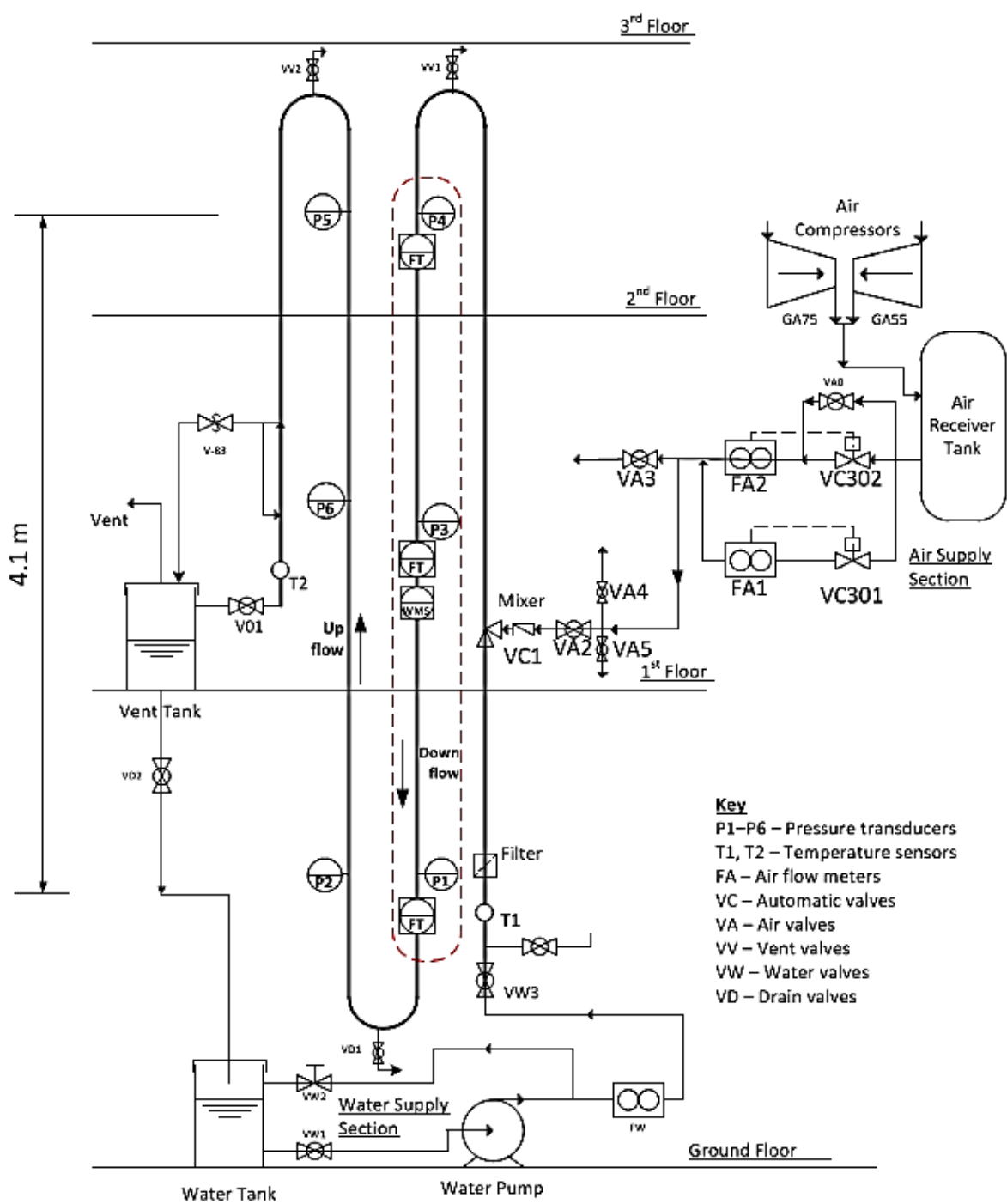

Figure 1: Serpent Rig air-water two-phase experimental facility

The test area consists of the flow loop which is an approximately 20-m long 4-in. (101.6 mm) internal diameter pipeline which includes four ABS plastic vertical upward flowing and downward flowing sections connected by three Perspex 180 degree bends. The two middle $6 \mathrm{~m}$ vertical pipes are fitted with various instruments where all data is collected. While the vertical section left of the $\mathrm{U}$ is the upward flowing section, the right hand arm of the $U$ is the downward flowing section which is the area of interest of this study where all data was collected. Installed instrumentation on the flow rig are conductance probes used for liquid film thickness measurements and a $32 \times 32$ capacitance wire mesh sensor (WMS) used for cross-sectionally averaged gas void fraction measurements which was used for flow regime identification. Their installed positions for this study are those within the dotted lines shown in Figure 1. The instrumentation on the Serpent Rig are as follows: two air flow meters (ranges of $0-150$, at an uncertainty of $0.5 \%$ full scale (F.S.) and $15-4250 \mathrm{Sm}^{3} / \mathrm{h}$, at $0.5 \%$ F.S., respectively), one water flow meter (0.06-16 litre/s, at $0.1 \%$ F.S.), and six GE Sensing UNIK 5000 pressure transducers $\left(0-1.5\right.$ barg, at $\pm 0.04 \%$ F.S.) of which two $\left(\mathrm{P}_{1}\right.$ and $\left.\mathrm{P}_{4}\right)$, installed in the downcomer, were used for the present study. Two temperature sensors (range of $0-100{ }^{\circ} \mathrm{C}$, at $0.5 \%$ F.S.) are installed at the entrance and exit of the rig. 
The relevant film thickness probes to this work are installed 46 pipe diameters from the top after the

Uncertainties in the liquid film mean velocity measurement can be introduced by following ways: (1) velocity distribution in the liquid film. Since the sensor electrode is flush mounted to the pipe, only conductivity values of the liquid in direct contact are registered; there is a discrepancy between the measured film velocity and the mean velocity, since the velocity profile in liquid film is not uniform (2) The transit time measurement uncertainty which is limited by the sampling frequency of conductivity from the film velocity sensors. In this work, a frequency of $1000 \mathrm{~Hz}$ was employed meaning a $1 \mathrm{~ms}$ acquisition interval. For a typical transit time of $40 \mathrm{~ms}$, this gives at least $\pm 2.5 \%$ error in time delay determination by cross-correlation. (3) The design of the sensor electrodes with respect to their dimensions, such that partial contact is initially obtained with the electrolyte rather than almost instantaneous full contact if the electrode dimensions were of otherwise infinitesimal size. As the insulator part in the sensor is $1.0 \mathrm{~mm}$ wide, thus the uncertainty caused by this should be less than $1.0 \%$ for one sensor, and overall $2.0 \%$ for two sensors. (4) The velocity of electrolyte mixing/diffusion, which is mainly related to the injection rate and diffusivity of the electrolyte. It is estimated that the aforementioned sources of uncertainty could collectively give as much as $\pm 8 \%$ error in the film velocity measurements, close to that reported by Al-Yarubi \& Lucas (2008) and Al-Yarubi (2010) in which similar method of film velocity determination in vertical air-water tests was used.. 
Table 2: Measured liquid velocities

\begin{tabular}{|c|c|c|c|c|c|c|c|c|}
\hline $\begin{array}{c}u_{S l} \\
\mathrm{~m} / \mathrm{s}\end{array}$ & $\begin{array}{c}u_{s g} \\
\mathrm{~m} / \mathrm{s}\end{array}$ & $\begin{array}{c}u_{I f} \\
\mathrm{~m} / \mathrm{s}\end{array}$ & $\begin{array}{c}u_{s l} \\
\mathrm{~m} / \mathrm{s}\end{array}$ & $\begin{array}{c}u_{s g} \\
\mathrm{~m} / \mathrm{s}\end{array}$ & $\begin{array}{c}u_{l f} \\
\mathrm{~m} / \mathrm{s}\end{array}$ & $\begin{array}{c}u_{s l} \\
\mathrm{~m} / \mathrm{s}\end{array}$ & $\begin{array}{c}u_{s g} \\
\mathrm{~m} / \mathrm{s}\end{array}$ & $\begin{array}{c}u_{l f} \\
\mathrm{~m} / \mathrm{s}\end{array}$ \\
\hline \multirow{9}{*}{0.1} & 1.44 & 1.38 & \multirow{9}{*}{0.3} & 1.39 & 1.63 & \multirow{9}{*}{0.7} & 4.21 & 2.43 \\
\hline & 3.02 & 1.46 & & 2.92 & 1.74 & & 5.61 & 2.65 \\
\hline & 4.6 & 1.56 & & 4.47 & 1.87 & & 8.15 & 2.91 \\
\hline & 6.2 & 1.72 & & 6 & 1.99 & & 10.5 & 3.09 \\
\hline & 9.38 & 1.93 & & 8.94 & 2.22 & & 14.45 & 3.14 \\
\hline & 12.47 & 2.06 & & 11.7 & 2.43 & & 17.91 & 3.22 \\
\hline & 18.39 & 2.34 & & 16.74 & 2.7 & & 20.59 & 3.24 \\
\hline & 23.66 & 2.45 & & 21.33 & 2.81 & & & \\
\hline & 28.87 & 2.51 & & 25.12 & 2.84 & & & \\
\hline \multirow{9}{*}{0.2} & 1.42 & 1.45 & \multirow{9}{*}{0.48} & 2.86 & 2.02 & \multirow{9}{*}{1.0} & 5.29 & 2.87 \\
\hline & 2.97 & 1.57 & & 4.36 & 2.23 & & 7.62 & 3.07 \\
\hline & 4.54 & 1.71 & & 5.84 & 2.44 & & 9.65 & 3.26 \\
\hline & 6.12 & 1.91 & & 8.6 & 2.54 & & 13.15 & 3.26 \\
\hline & 9.18 & 2.14 & & 11.16 & 2.72 & & 15.98 & 3.38 \\
\hline & 12.08 & 2.32 & & 15.63 & 2.87 & & 18.56 & 3.38 \\
\hline & 17.51 & 2.52 & & 19.62 & 3.02 & & & \\
\hline & 22.41 & 2.68 & & 22.87 & 2.92 & & & \\
\hline & 26.61 & 2.71 & & & & & & \\
\hline
\end{tabular}

The data acquisition system comprises of DeltaV and LabVIEW software. While the DeltaV system is for recording and controlling the air flow rates with the sampling rate fixed at $1 \mathrm{~Hz}$, LabVIEW is for acquiring and recording the pressures, film thicknesses and fluid temperatures with a sampling rate of $100 \mathrm{~Hz}$. Further details of the film thickness probes, WMS, other instrumentation, and data acquisition can be found in Almabrok (2014).

\subsection{Film thickness and flow development}

The film thickness was measured at three different axial positions downstream of inverted U-bend. It is a mean value of four circumferential measurements made on the probe spool. Three such spool assemblies installed on the downward flowing section of the test rig were used to obtain the mean film thickness which enables the study of its axial variation. Axial positions at the top, middle, and bottom of the downward flowing part of the rig are respectively at 10,30 and 46 pipe diameters from the inverted U-bend. Figure 2 shows normalised mean film thicknesses obtained from the conductance probes at the stated axial positions. These normalised film thicknesses are defined as the ratios of film thicknesses at other $\mathrm{L} / \mathrm{D}$ positions to that at $\mathrm{L} / \mathrm{D}=46$ (i.e. $t_{n o r m}=t / t_{L / D=46}$ ). This means that $t_{n o r m}$ at 46 pipe diameters is unity. It can be seen that there is minimal change in the normalised mean film thickness between the middle and bottom positions. This signifies a reasonably developed flow which is expected and is due to the prevailing influence of gravity on downwards flow. Therefore, the film thicknesses used for the analyses in this paper are those at $\mathrm{L} / \mathrm{D}=46$, representing a film thickness in fully developed downwards annular flow. 


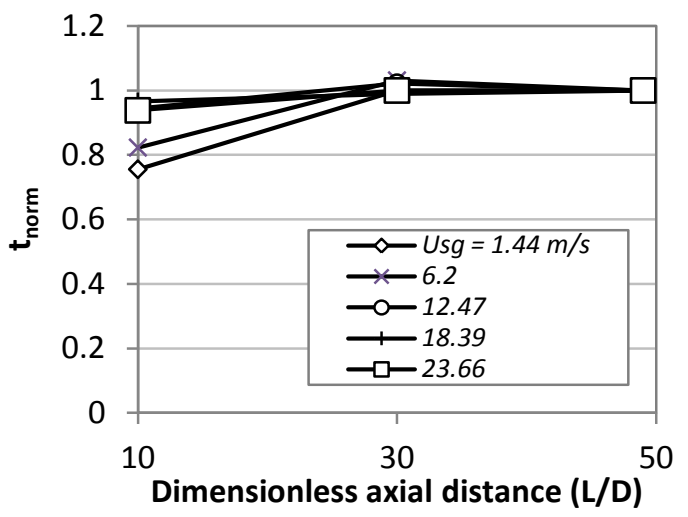

(a)

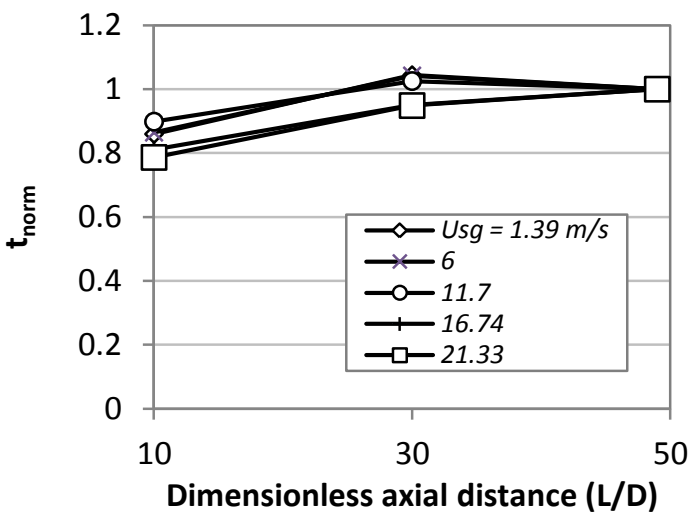

(b)

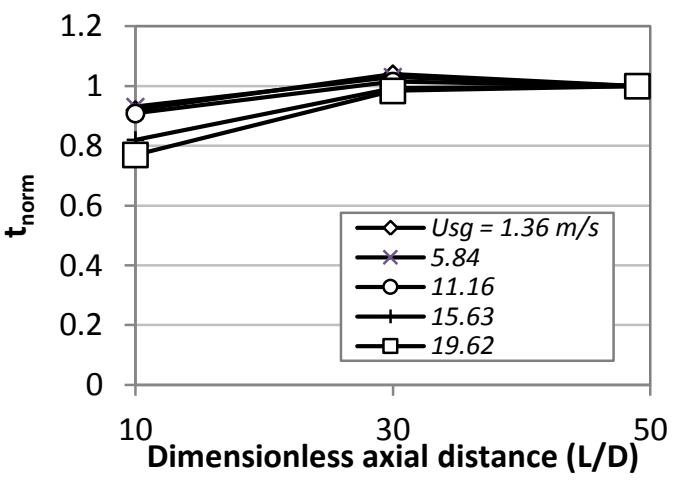

(c)

Figure 2: liquid film thickness variation along the axial distance of $\mathrm{L} / \mathrm{D}=10,30$, and 46 (top middle and bottom respectively) from inverted U-bend for (a) $u_{S l}=0.1 \mathrm{~m} / \mathrm{s}$ (b) $u_{S l}=0.3 \mathrm{~m} / \mathrm{s}$ and (c) $u_{S l}=1.0$ $\mathrm{m} / \mathrm{s}$, (Almabrok et al 2015).

For vertical upflows, liquid film thickness decreases with increasing superficial gas velocity. In the case of vertical downwards flows, as can be seen from Figure 3, for low liquid flow rates $\left(u_{s l} \leq 0.48\right.$ $\mathrm{m} / \mathrm{s}$ ) there is an initial increase before the expected progressive decrease in the mean film thickness as the gas flow rate is increased. This behaviour might be explained by considering the velocity slip at the liquid film/gas core interface. In low gas flow rates, falling film velocity could be significantly higher than the local gas velocity. At such conditions the falling liquid film glides past the slower gas thereby sweeping liquid droplets into the gas core and hence reducing the thickness of the falling film. This entrainment should reach a minimum when there is zero velocity slip in the liquid film/gas core interface corresponding to a maximum of the liquid film thickness. Conversely, when the gas velocity is increased leading to gas moving faster than the liquid film in the interface, there will be increased interfacial shear, again resulting in increased entrainment. After the maxima in the mean film thickness, it then asymptotically reduces with increasing $u_{s g}$. For those high liquid flow rates $\left(u_{s l}>\right.$ $0.7 \mathrm{~m} / \mathrm{s}$ ), annular flow can only be established in the downcomer with a $U$ bend following it if the gas velocity is significantly high, as reported by Almabrok (2014). Thus in those annular flows the film thickness progressively decreases against the gas velocity due to increased film velocity and liquid entrainment. 


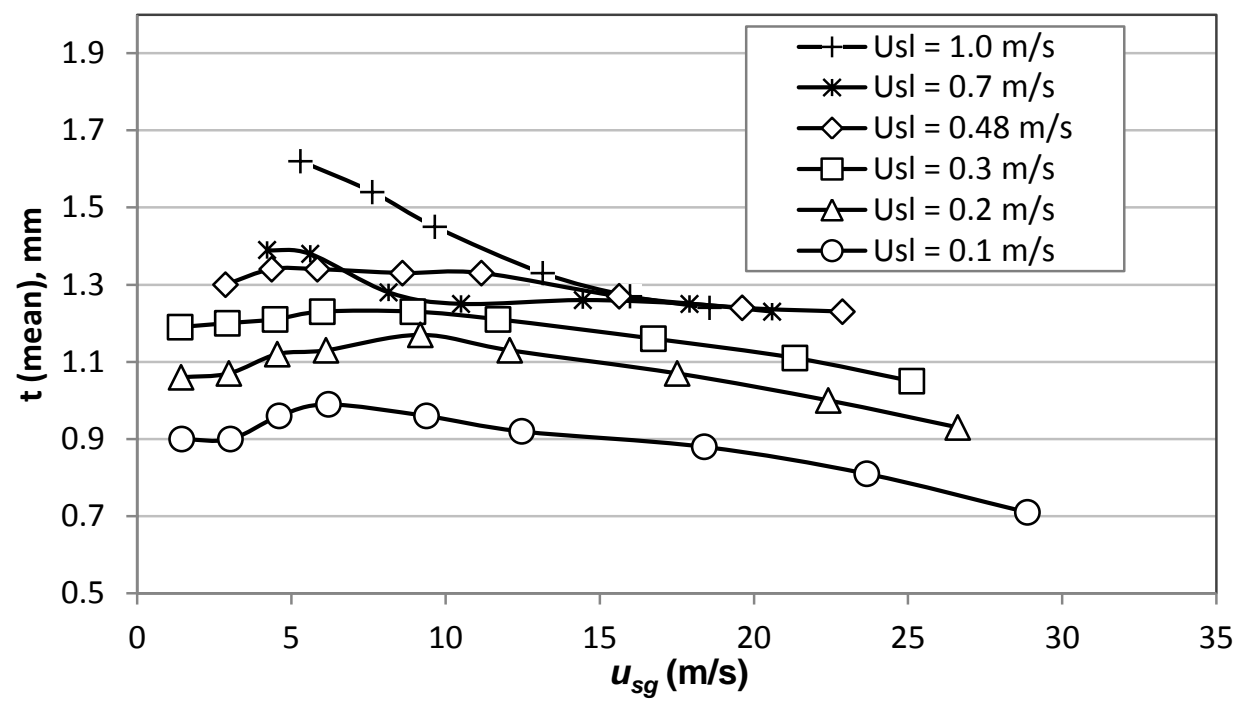

Figure 3: Variation of liquid film thickness with superficial gas velocity at different liquid superficial velocities taken at $\mathrm{L} / \mathrm{D}=46$ from inverted $\mathrm{U}$-bend entrance region

\subsection{Film velocity measurements and entrained droplet fraction}

It is important to note that there are large differences in gas velocity and liquid film velocity as the superficial gas velocity is increased. An increase in slip velocity results which in turn brings about rising shear at the gas-liquid interface. Several mechanisms have been put forward as to how this shearing contributes to liquid breakup hence entrainment; these include a "roll wave" mechanism as observed by early researchers such as Green (1950) using high speed photography and Lane's (1951) wave "undercutting" mechanism.

These measured velocities were used to calculate the entrainment rate of water droplets into the gas core. The entrained droplet fraction is given by

$$
e=\frac{W_{E}}{W_{T}}=\frac{W_{T}-W_{l f}}{W_{T}}
$$

where $W_{E}$ is the droplet entrainment rate, $W_{T}$ is the total liquid mass flow rate and $W_{l f}$ is the liquid film mass flow rate. The liquid film flow rate $W_{l f}($ in $\mathrm{kg} / \mathrm{s})$ is calculated as follows

$$
W_{l f}=\rho_{l} u_{l f} A_{l f}
$$

where $U_{L F}$ is the measured liquid film velocity and $A_{l f}$ is the liquid film wetted cross-sectional area determined by

$$
A_{l f}=\pi\left(D t-t^{2}\right)
$$

\subsection{Calculation of interfacial properties from experimental measurements}

Eighty data points were obtained for this study in the range of $R e_{g}=8400-187000$ and $R e_{l f}=646-$ 9700. Calculation of the liquid film Reynolds number is calculated using the relation

$$
R e_{l f}=4 W_{l f} / \pi D \mu_{l}
$$


The interfacial friction factor is estimated from measured pressure gradient by taking a momentum balance at the gas-liquid interface with the assumption that the flow is fully developed

$$
f_{i}=\frac{2 \tau_{i}}{\rho_{g} u_{s g}^{2}}
$$

where $\tau_{i}$ is the interfacial friction factor given by

$$
\tau_{i}=\left(-\frac{d P}{d z}+\rho_{c} g\right) \frac{D-2 t}{4}
$$

This equation assumes a uniform film thickness around the pipe cross-section.

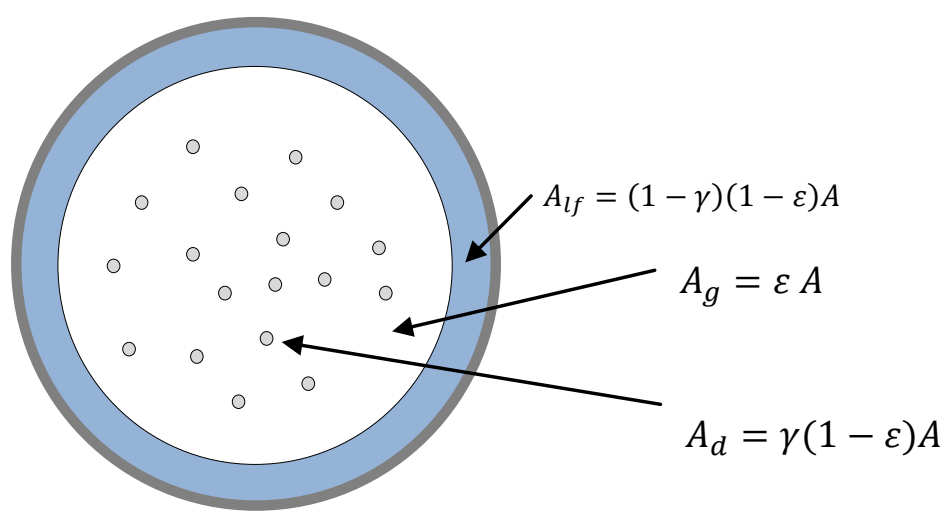

Figure 4: Representation and notation of the various phase splits (film, gas and droplets) occupying the total pipe area (Adapted from Cioncolini et al. 2012)

Here it should be noted that since there is significant droplet entrainment in the gas core, as is depicted in Figure 4, pure gas properties are replaced by linearly phase-averaged density of droplet laden gas core.

$$
\rho_{c}=\left(1-\varepsilon_{c}\right) \rho_{l}+\varepsilon_{c} \rho_{g}
$$

Historically, obtaining satisfactory mixing rule has not been straight forward, with different authors preferring to define different two-phase viscosities. Two typical correlations for the viscosity of twophase mixture are that of the reciprocal mean by Isbin et al. (1957) and that by Dukler et al. (1962) using the gas quality. For the present study however, we have used a linear phase-averaged mixing rule as defined by Cicchitti et al. (1960) and Hewitt \& Hall-Taylor (1970); it was recently used by Cioncolini et al. (2009a, 2009b); and Cioncolini \& Thome (2010) as

$$
\mu_{c}=\left(1-\varepsilon_{c}\right) \mu_{l}+\varepsilon_{c} \mu_{g}
$$

where $\varepsilon_{c}$ is the gas core void fraction estimated as

$$
\varepsilon_{c}=\frac{\varepsilon}{\varepsilon+\gamma(1-\varepsilon)}
$$

with $\varepsilon$ being the cross-sectionally averaged void fraction and $\gamma$ the droplet holdup, estimated by ignoring the slip between the entrained droplets and the gas as follows 
where $e$ is the entrained droplet fraction defined in Equation (1) and $x$ is the gas quality, ratio of the gas mass flux to the total mas flux. It has been pointed out that as the homogenous model neglects the phase slip between the gas and liquid, it is theoretically more suited to two phase flows characterised by proper mixing between the phases e.g. dispersed bubbly flow and less accurate in the case of separated flow where slip is more prevalent such as annular flow. Even so, Hewitt \& Hall-Taylor (1970) have shown that it can equally handle annular flow insofar as the mixture viscosities and densities are appropriately defined.

\subsection{Uncertainty of frictional factor estimation from the experimental data}

It is vital to estimate the error in the interfacial friction factor calculated from experimental measurements. In order to do this, we substitute Equation (6) in Equation (5) yields the relationship for calculating interfacial friction factor in terms of all the measured experimental quantities of pressure gradient, liquid film thickness, and core density (which is a function of the measured liquid film velocity):

$$
f_{i}=\frac{\left(-\frac{d P}{d z}+\rho_{c} g\right)(D-2 t)}{2 \rho_{g} u_{s g}^{2}}
$$

The quantities that are dominant in the uncertainty determination from the equation above are $-\frac{d P}{d z}$, $\rho_{c}$, and $t$. Assuming these three measured variables are independent, the uncertainty in $f_{i}$ caused by the random errors in the measurements can be given as a relative error as follows:

$$
\frac{\delta f_{i}}{f_{i}}=\sqrt{\frac{(\delta A)^{2}+\left(g \delta \rho_{c}\right)^{2}}{\left(A+\rho_{c} g\right)^{2}}+\left(\frac{2 \delta t}{D-2 t}\right)^{2}}
$$

where $A=-\frac{d P}{d z}$ and the $\delta$ represent the uncertainties in the respective quantities in bracket. For pressure gradient measurements, the full scale uncertainty is given as $\delta A= \pm 0.21 \mathrm{~Pa} / \mathrm{m}$; for the film thickness, $\delta t= \pm 0.10 \mathrm{~mm}$ F.S.; while that of the film velocity is $\delta u_{l f}= \pm 0.18 \mathrm{~m} / \mathrm{s} \mathrm{F.S.} \mathrm{The}$ uncertainty in the gas core density is not readily available since it is a derived quantity obtained from the liquid film velocity. Therefore, the uncertainty in $\rho_{c}$ is deduced from its definition given in Equation (7). Details of its derivation are presented in the Appendix. Finally, the percentage error in $f_{i}$ for each experimental condition is given as:

$$
\% \operatorname{Err}\left(f_{i}\right)=\frac{\delta f_{i}}{f_{i}} \times 100 \%
$$

The plot in Figure 5 shows the percentage errors calculated from Equation (13) against the superficial gas velocity $u_{s g}$. As can be seen, overall the majority of the percentage errors are within $7.5 \%$. However it was noted that a peaking of the uncertainty values occurring at around $u_{s g}=10 \mathrm{~m} / \mathrm{s}$ for each set of superficial liquid velocity. This peaking could possibly due to the fact that minimum slip occurs at the related gas velocity, giving rise to comparatively larger relative errors. As can also be seen from the figure, a few of the percentage errors were as much as $12-21 \%$ at $u_{s l}=0.1,0.2$, and 0.3 $\mathrm{m} / \mathrm{s}$. 


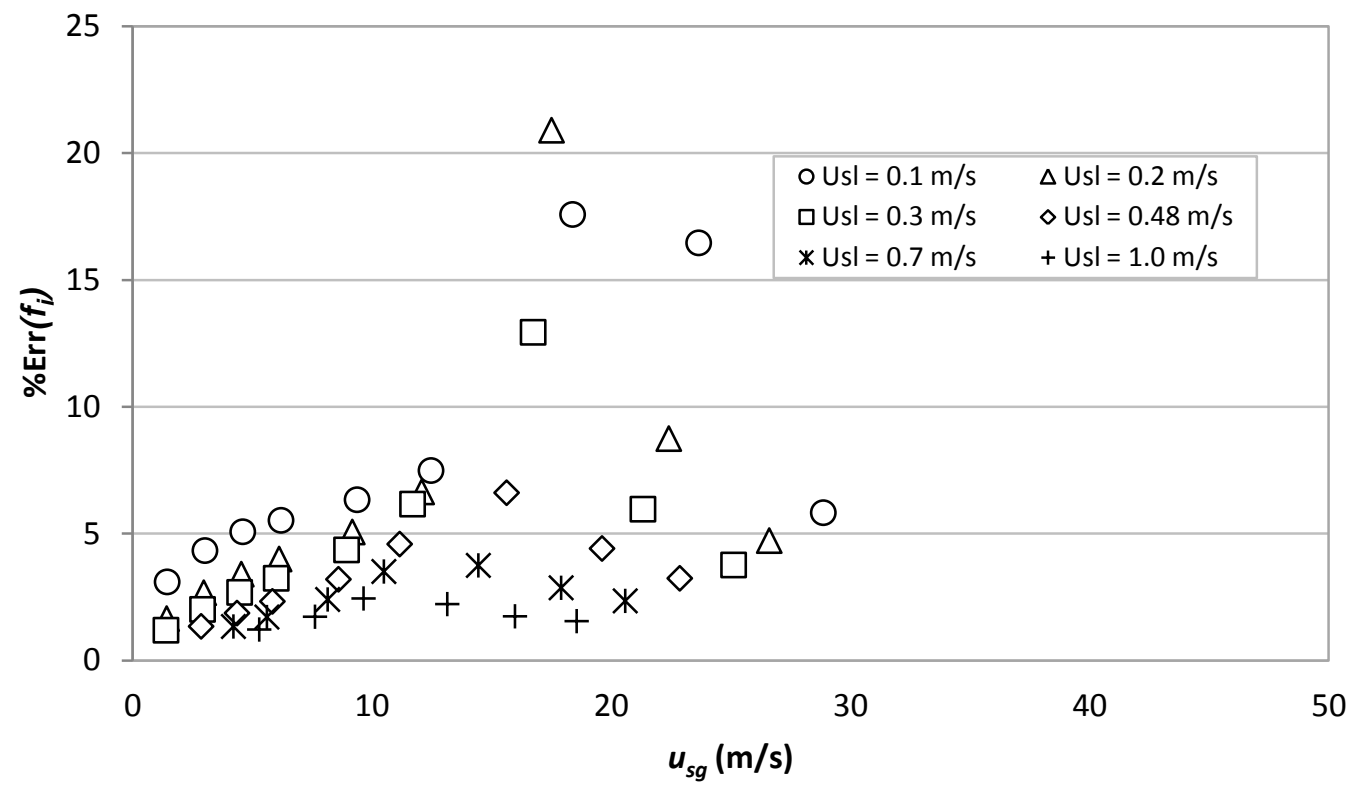

Figure 5: Percentage error in $f_{i}$ for different experimental conditions

\subsection{Comparison of experimental interfacial friction factor with published correlations}

Henstock \& Hanratty (1976) described a method to predict the height of the liquid film and interfacial friction factor in both upward and downward annular flow in circular pipes. For downward flow, they used pipe flow data from Chien \& Ibele (1964), Charvonia (1959), and Wright \& Laufenbrenner (1975) obtained from 50.8, 63.5 and $25.4 \mathrm{~mm}$ respectively. Henstock \& Hanratty argued that the wave surface of relatively thick films is well represented by two characteristic lengths t/D and $\mathrm{t}^{+}$which describe Bergelin et al's (1959) roughened sand surface analogy of the gas-liquid interface.

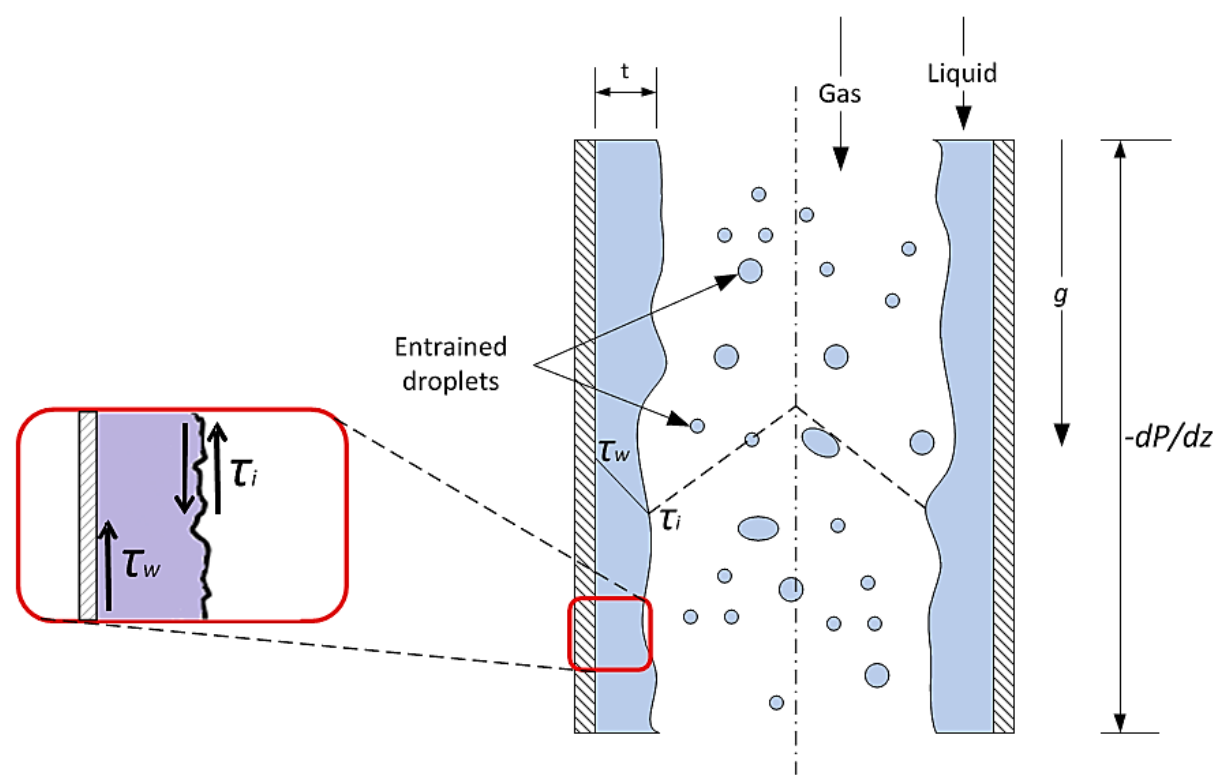

Figure 6: Flow configuration for vertical downwards annular two-phase flow

However, for very thin films the waves are small enough for $f_{i}$ to be approximated by $f_{s}$, the friction factor of a smooth pipe. They then reasoned that at this point, the true shear stress has a magnitude between the wall shear and the interfacial shear stress. They therefore offered to correct this 
interfacial shear with a characteristic shear stress $\tau_{c}$ as a weighted sum dominated by the wall shear stress as

$$
\tau_{c}=\frac{2}{3} \tau_{w}+\frac{1}{3} \tau_{i}
$$

where the wall shear stress which acts in opposition to the direction of flow (Figure 6), is given as

$$
\tau_{w}=-\frac{d P}{d z} \frac{D}{4}+\rho_{l} g \frac{D}{4}\left(1-\left(\frac{D-2 t}{D}\right)^{2}\right)+\rho_{c} g \frac{D}{4}\left(\frac{D-2 t}{D}\right)^{2}
$$

The first term on the right hand side represents the total measured pressure gradient and the other two are the gravitational pressure gradients as contributed by the liquid film and the droplet-laden gas core respectively. Here, it is assumed that the system is at equilibrium and since it is adiabatic, the accelerational pressure gradient is negligible. The factor $[(D-2 t) / D]^{2}$ is a measure of the void fraction given the film thickness measurement and assuming it is uniform on the pipe periphery. The dimensionless film thickness $t_{g}^{+}=t v_{c}^{*} / v_{l}$ akin to $\mathrm{y}^{+}$the friction distance parameter is hence redefined in terms of the liquid film thickness as follows

$$
t^{+}=\frac{t}{v_{l}} \sqrt{\frac{\tau_{c}}{\rho_{l}}}
$$

with a rather lengthy theoretical argument, Henstock \& Hanratty were able to eliminate the dependence of the frictional forces acting on the liquid film on $t^{+}$and derived a modified Martinelli flow parameter $F$ defined as

$$
F=\frac{M}{R e_{g}^{0.9}} \frac{v_{l}}{v_{g}} \sqrt{\frac{\rho_{l}}{\rho_{g}}}
$$

where

$$
M=\left[\left(0.707 R e_{l f}^{0.5}\right)^{2.5}+\left(0.0379 R e_{l f}^{0.9}\right)^{2.5}\right]^{0.4}
$$

It should be noted that this flow parameter only holds for fully turbulent flow (with entrainments) where $R e_{l f} \rightarrow \infty$ and is negligible for laminar flow as $R e_{l f} \rightarrow 0$ where interfacial drag is trivial. They used this approach to study experimental results where the pressure gradient, film thickness and film flow rate were measured and then derived a relation for the interfacial friction factor $f_{i}$ in terms of $F$ by fitting the data finding reasonable agreement as follows

$$
\frac{f_{i}}{f_{s}}=1+1400 F
$$

where $f_{s}$ is the single phase friction factor given by

$$
f_{S}=0.046 R e_{g}^{-0.2}
$$

We tested this against our own experimental data as is shown in Figure 7. The correlation exhibits huge deviations resulting in both over- and under-predictions of our data by a factor of up to 1500 thereby being consistent with Asali et al.'s (1985) assertion that the correlation is unsuitable for capturing the effect of pipe diameter such as the $101.6 \mathrm{~mm}$ ID used for this study. 


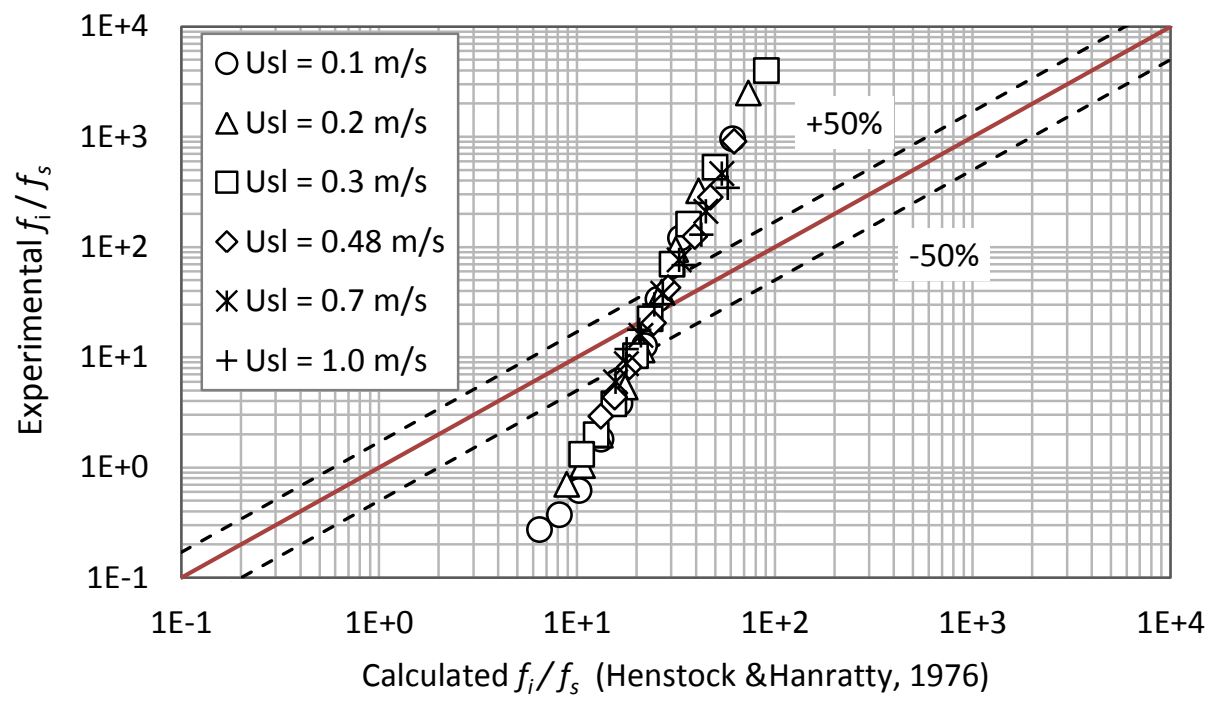

Figure 7: Prediction of interfacial friction factor by Henstock \& Hanratty (1976) vs experimental friction factor

In their attempt to account for pipe diameter, Asali et al. (1985) showed that $\left(f_{i} / f_{s}-1\right) \propto t_{g}^{+}$is a better representation of dimensionless film thickness than $\left(f_{i} / f_{s}-1\right) \propto \frac{t}{D}$ for gas velocities greater than $25 \mathrm{~m} / \mathrm{s}$. Where $t_{g}^{+}$the dimensionless film thickness based on the gas properties is defined as

$$
t_{g}^{+}=\frac{t}{v_{g}} \sqrt{\frac{\tau_{i}}{\rho_{g}}}
$$

For the roll wave regime, (at $R e_{l f}>R e_{l f c}$, the critical Reynolds number at the start of entrainment) they found that $t_{g}^{+}$correlated well with $R e_{l f}$ for downflows as follows

$$
t_{g}^{+}=0.19 R e_{l f}^{0.7} \frac{v_{L}}{v_{g}} \sqrt{\frac{\rho_{l} \tau_{i}}{\rho_{g} \tau_{c}}}
$$

This was then correlated with the interfacial friction factor

$$
\left(f_{i} / f_{s}-1\right)=0.45 R e_{g}^{-0.2}\left(t_{g}^{+}-5.9\right)
$$

Our data is however not well described by this correlation as show in Figure 8. At high liquid velocities (corresponding to the thick films), $f_{i} / f_{s}$ are far more over-predicted than at lower liquid velocities. 


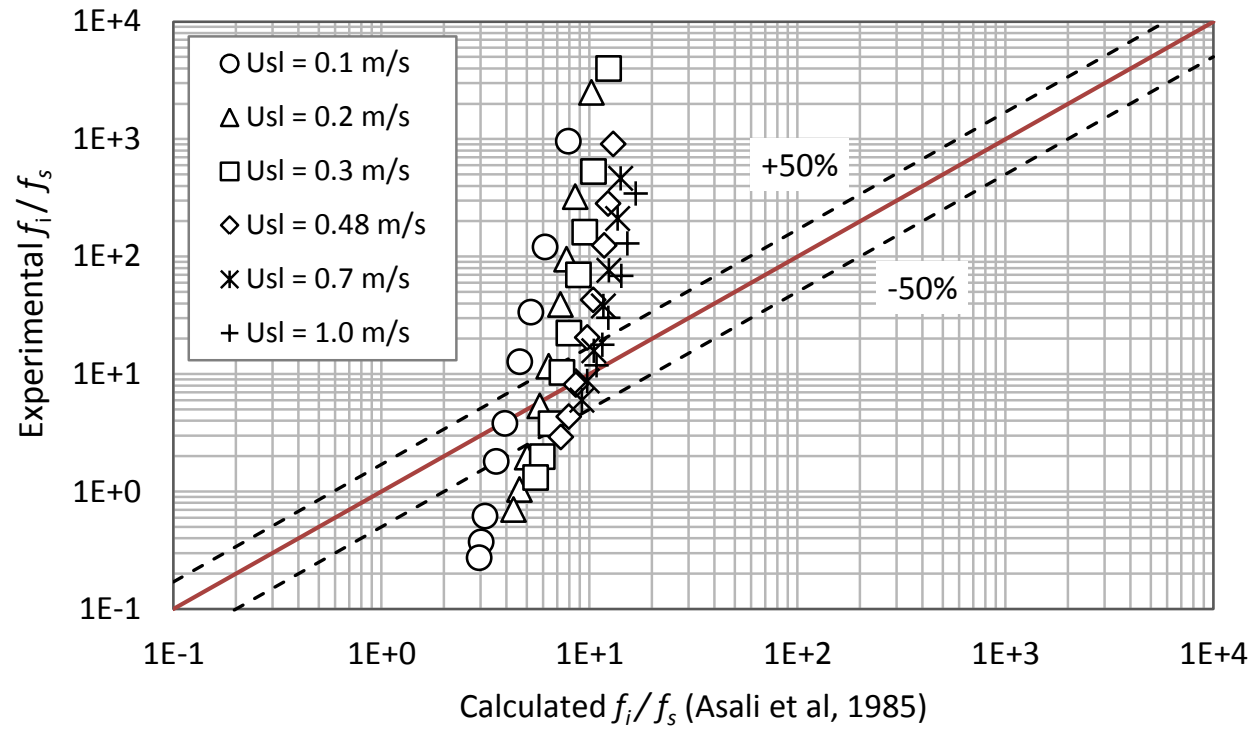

Figure 8: Prediction of interfacial friction factor by Asali et al. (1985) vs experimental friction factor

This is not surprising given that Asali et al (1985) correlated their data at high gas velocities above 25 $\mathrm{m} / \mathrm{s}$ whereas for the present study, the gas velocities are within the range $1.41-28.87 \mathrm{~m} / \mathrm{s}$ with only a few measurements taken above $25 \mathrm{~m} / \mathrm{s}$. Despite the failure of Asali et al.'s (1985) correlation to adequately describe our data, it is noted that their scheme of using the group $t_{g}^{+} R e_{g}^{-0.2}$ (adapted from Asali, 1983) very well correlates friction factor data with entrainment better than $t_{g}^{+}$.

Fukano et al. (1991) investigated interfacial shear using an air-water system in three tube diameters of 10,16 , and $26 \mathrm{~mm}$ within the range of $20-60 \mathrm{~m} / \mathrm{s}$ and $0.006-0.1 \mathrm{~m} / \mathrm{s}$ superficial gas and liquid velocities corresponding to $R e_{g}$ and $R e_{l}$ values of 12720-99218 and 67-2900 respectively. The very low liquid velocities and relatively high gas velocities (as similarly described in

) give large slip ratios hence high shear potentially leading to large droplet entrainments. Interestingly, Fukano et al. in their analyses assumed a smooth film with no entrainments. Measurements were carried out in horizontal annular flow and in both upwards and downwards vertical flow. They correlated their interfacial friction factor as a function of the superficial liquid and gas Reynolds numbers and notably, the Lockhart-Martinelli parameter. They obtained the following empirical model which they claimed holds irrespective of tube size and pipe orientation

$$
\left(f_{i} / f_{s}-1\right)=8.53 \times 10^{-4} X^{2.82} R e_{g}^{2} R e_{l}^{-1}
$$

where $X$ is the Lockhart-Martinelli flow parameter defined as follows

$$
X=\sqrt{\frac{\Delta P_{l O}}{\Delta L} / \frac{\Delta P_{g O}}{\Delta L}}
$$

The quantities $\Delta P_{l o} / \Delta L$ and $\Delta P_{g o} / \Delta L$ are the single phase pressure gradients as if the phases are flowing alone in the pipe. They are respectively calculated by the Darcy-Weisbach formulae for single phase pressure loss

$$
\Delta P_{l o} / \Delta L=\frac{1}{2}\left(f_{l} / D\right) \rho_{l} u_{s l}^{2}
$$




$$
\Delta P_{g o} / \Delta L=\frac{1}{2}\left(f_{g} / D\right) \rho_{g} u_{s g}^{2}
$$

Where $f_{l}$ and $f_{g}$ are the single phase friction factors for smooth pipes

$$
f_{L}=0.046 R e_{l}^{-0.2}
$$

$f_{g}=f_{s}$ as defined in Equation (20). Figure 9 shows our data compared to this model. There is no systematic agreement with respect to superficial liquid velocities; instead, agreement exists at middle points across most liquid velocities. However, large errors still remain at many data points with overand under-predictions of up to 1000 times the experimental values.

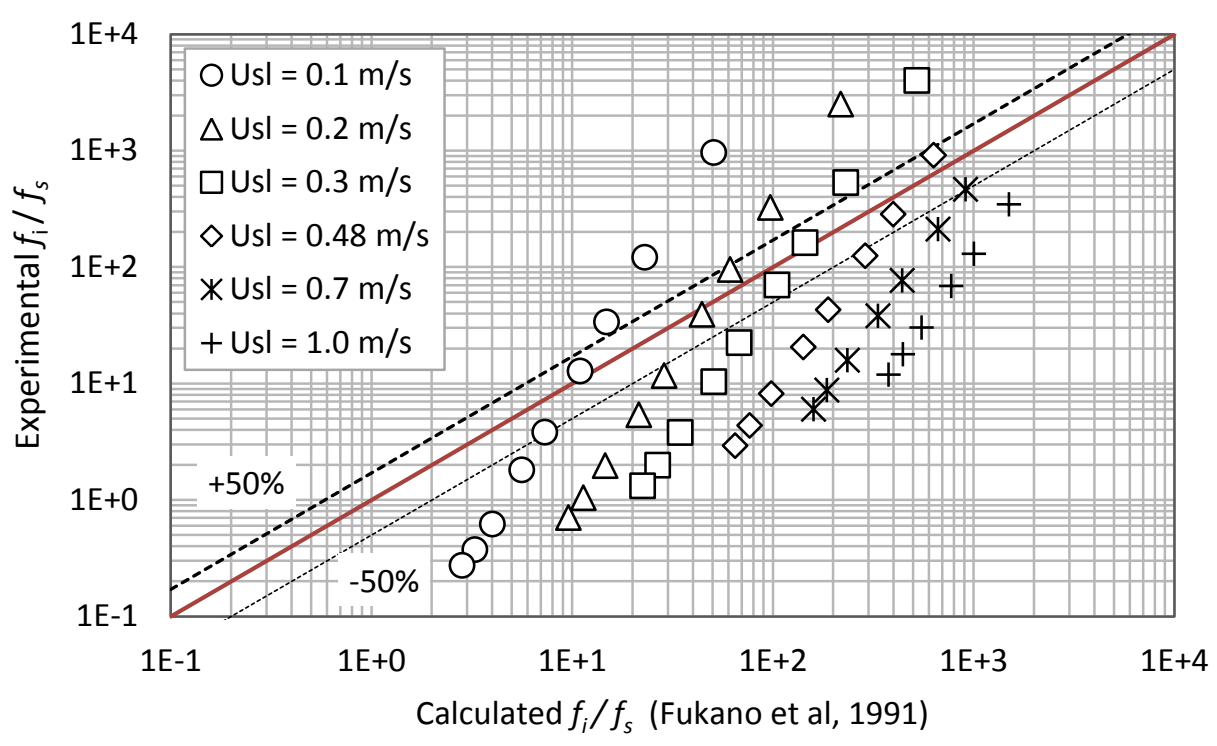

Figure 9: Prediction of interfacial friction factor by Fukano et al. (1991) vs our experimental friction factor

Hajiloo et al. (2001) used the same correlating method as Asali et al. (1985) for interfacial friction data obtained using four pipe diameters ranging from 15.6-41.2 mm. They used the group $t_{g}^{+} R e_{G}^{-0.7}$ and obtained the correlation for interfacial friction factor

$$
f_{i} / f_{s}=125.2 t_{g}^{+1.51} R e_{g}^{-1.05}
$$

The effect of pipe diameter on interfacial friction factor was apparent in their correlation when plotted against the experimental data obtained from the four different pipes in the study. They used superficial instead of the liquid film Reynolds number to calculate $t_{g}^{+}$using Equation (22) while noting that their data was without entrainment. They clearly pointed out that entrainment was undesirable for the design application (falling films in scrubbers) which motivated their study and have made no attempt to measure or account for droplet entrainment. Here, we stress that entrainment is important in dispersed annular flow frequently encountered in gas condensate pipe systems and other industrial applications involving turbulent liquid films flowing with a gas core in conduits as it alters the film hydrodynamics. 


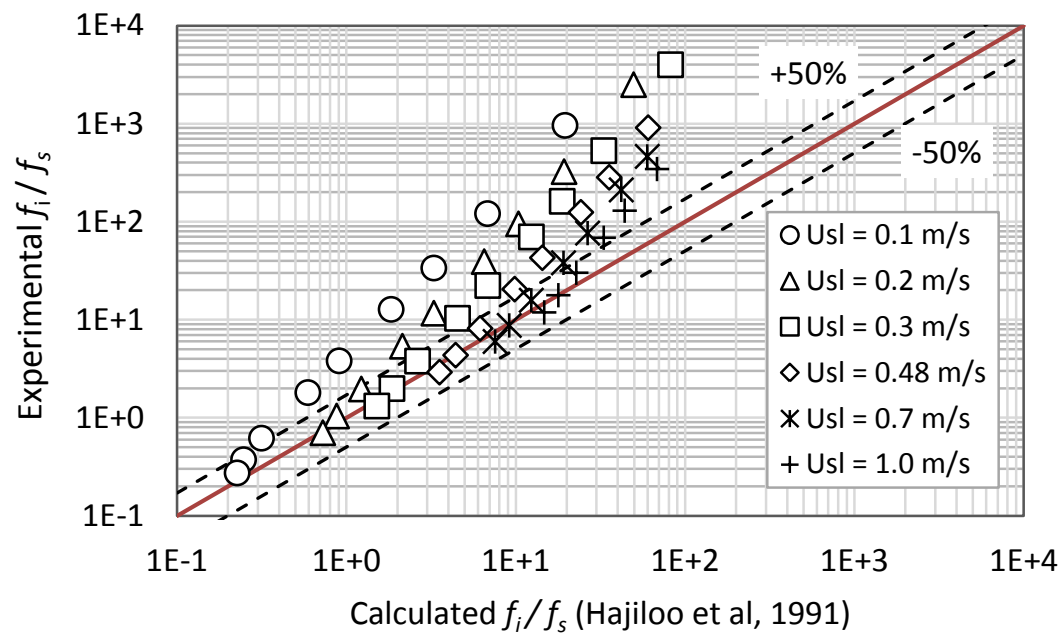

Figure 10: Prediction of interfacial friction factor by Hajiloo et al. (2001) vs our experimental friction factor

Nonetheless, as can be seen in Figure 10, their empirical model provides better predictions with respect to our data over a wider range of conditions than Henstock \& Hanratty (1976) and Asali et al. (1985). Particularly good are the predictions for the thicker films at higher liquid Reynolds numbers where the velocities of both phases are closer (less phase slip) and there is less interfacial shear. As a result, the entrainment is minimal. These conditions very much resemble those in which Hajiloo and co-workers obtained their data. More importantly, this relative agreement suggests that the model could able to capture the effect of pipe diameter within this short range of conditions.

Other investigators have used various approaches in modelling two-phase frictional pressure drop in downward annular flow by treating both phases as a homogeneous mixture. In this case the friction factor is termed a two-phase friction factor and in reality, such methods are flow regime independent notably in the style of Lockhart -Martinelli (1949). The works of Klausner et al. (1991), Dalkilic et al. (2009) and Bhagwat et al. (2012) are cases in point. Hewitt \& Hall-Taylor (1970) have shown using the data of Gill et al. (1964) that the homogeneous model method is less accurate than flow regime specific methods.

\section{New empirical correlation}

In light of the various shortcomings of the published correlations, it is imperative to attempt to correlate our data separately which are characterised by large entrainments due to roll wave regime type entrainment caused by large shear resulting from the huge velocity differences between the phases. These resemble the premises used by Asali (1983), Asali et al. (1985) to correlate their data which were improvements to the rough sand analogue used by Henstock \& Hanratty (1976). As turbulent two-phase flow consists of complex interaction of forces and phenomena, Hajiloo et al. (2001) noted that the rough sand analogue is simplistic. However, none of the correlations developed by these researchers described our data satisfactorily.

We attempted using Asali et al.'s (1985) method, but this failed to collapse the data (Figure 11) as well as their modified method as utilised by Hajiloo et al. (2001) (Figure 12). The latter method involves plotting $f_{i} / f_{s}$ against the dimensionless group $t_{g}^{+} R e_{g}^{-0.7}$ and fitting a power law curve through the data points. As earlier mentioned, this is in fact a modification of the correlation scheme 
of Asali et al. (1985) where $t_{g}^{+} R e_{g}^{-0.2}$ was originally used. The former scheme produced a correlation coefficient $\mathrm{R}^{2}$ value of 0.8078 immensely inferior to the 0.9671 value obtained for the latter method.

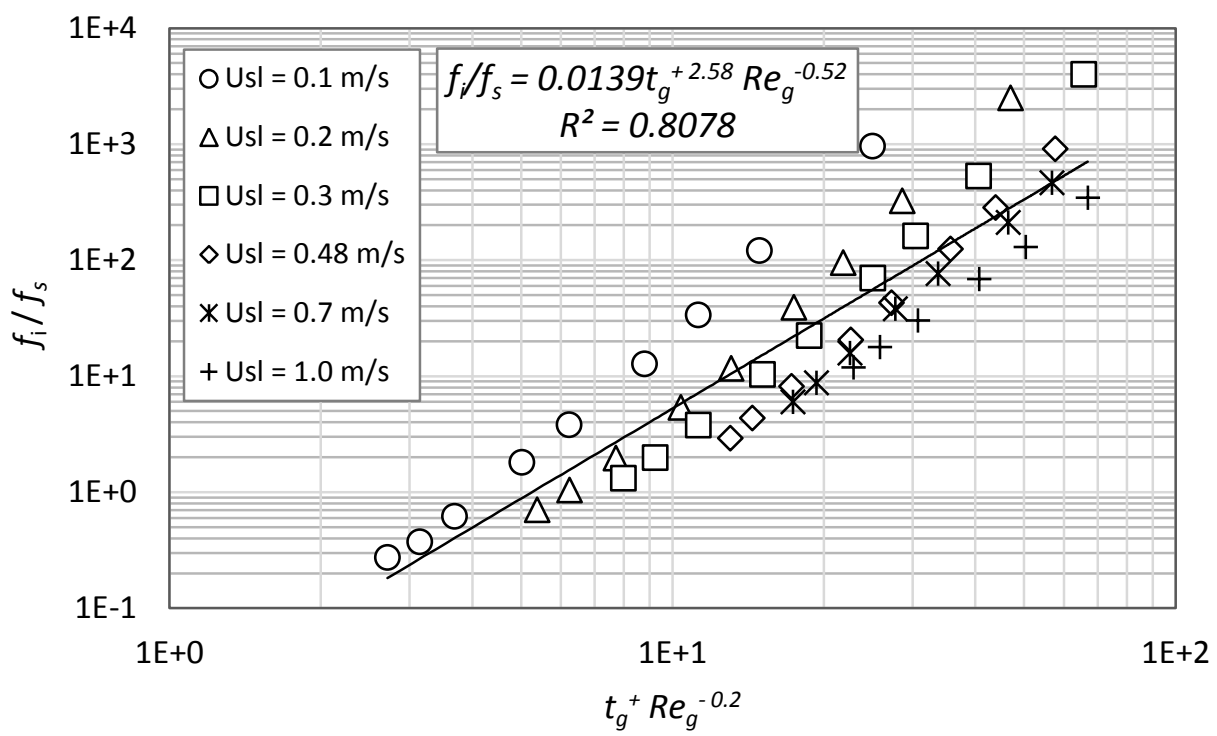

Figure 11: Attempted correlation of downward flow air-water two-phase interfacial friction factor using the method of Asali et al. (1995)

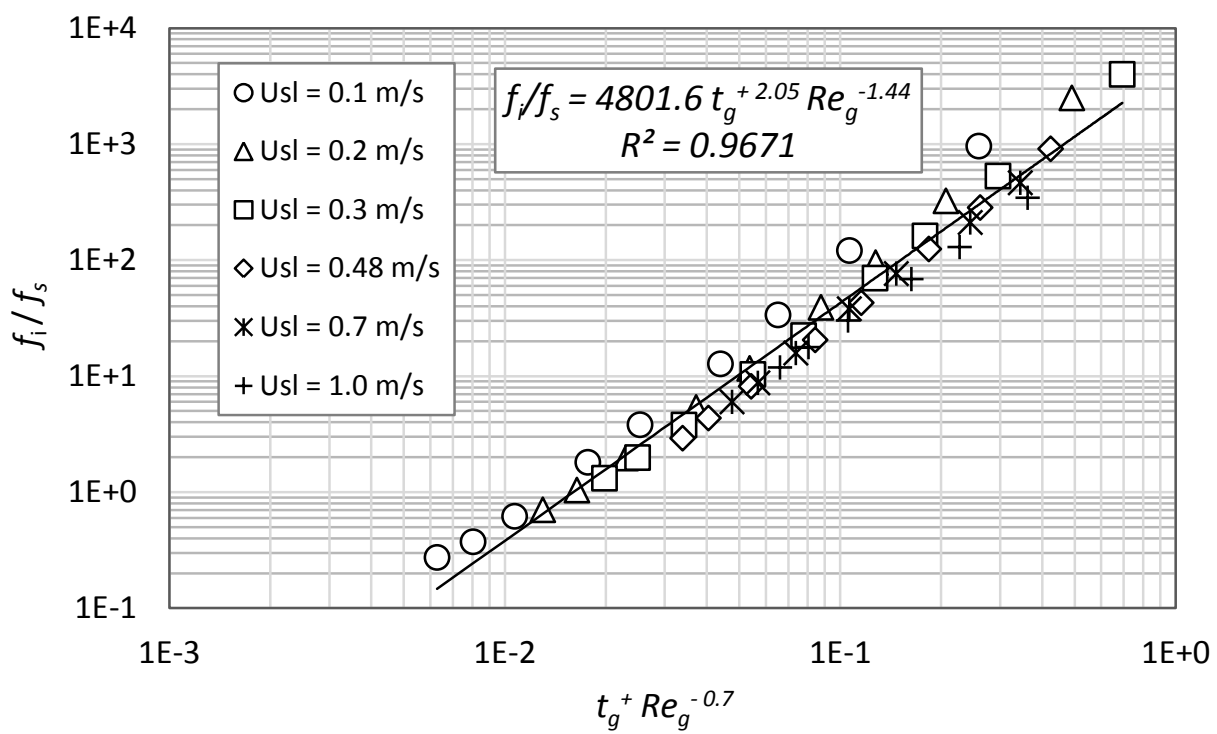

Figure 12: Correlation of interfacial friction factor for downward annular air-water two-phase flow

Therefore, we propose the following empirical correlation for estimating the interfacial friction factor in downwards air-water two-phase annular flow in circular tubes for large diameter pipes, those with diameters up to $101.6 \mathrm{~mm}$

$$
f_{i} / f_{s}=4801.6 t_{g}^{+2.05} \operatorname{Re}_{g}^{-1.44}
$$

Where $t_{g}^{+}$is calculated using 
In cases where liquid film thickness measurements $t$ are not available, a good correlation for its calculation is that of Almabrok et al. (n.d.) developed for both small and large pipes of up to 101.6 $\mathrm{mm}$. Knowledge of the entrained droplet fraction is needed to calculate the droplet-laden core properties which are in turn needed to calculate $\tau_{i}$ given in Equation (6). The correlation of Cioncolini $\&$ Thome (2012) can be used to estimate this in the absence of measured droplet fraction data.

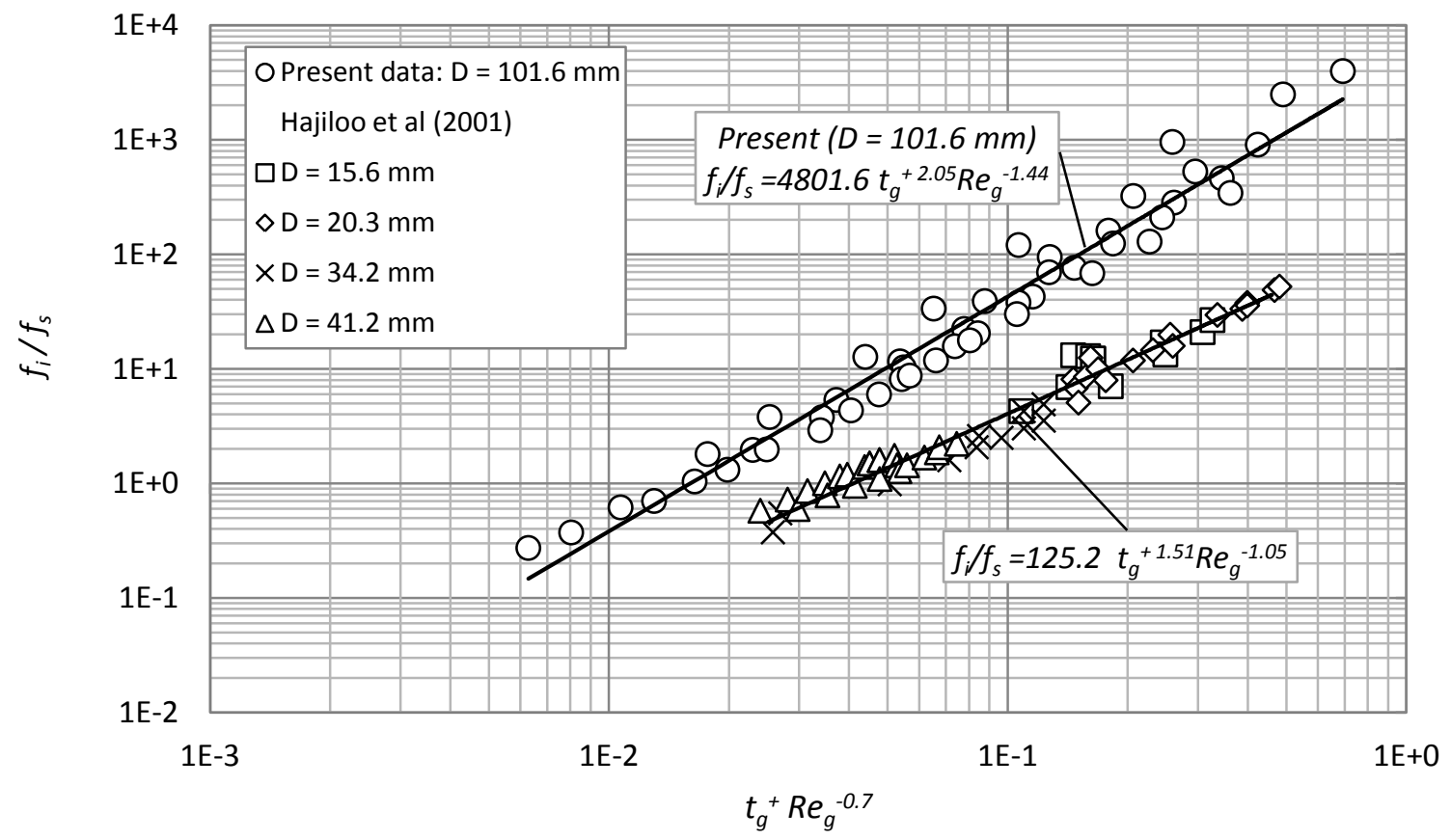

Figure 13: Effect of pipe diameter on annular downflow interfacial friction factor

To give some perspective on the effect of pipe diameter, we plotted Hajiloo et al.'s (2001) correlation side by side Equation (30) in Figure 13. A large difference is seen between the two models which can give quite erroneous results if one is used in place of the other for interfacial friction factor estimations. We therefore tentatively suggest the use of Equation (30).

Also, we have attempted to find a new correlation for both large and small pipes using the data of Hajiloo et al (2001) from four different pipe diameters ranging between 15.6-41.2 mm and our large pipe data of $101.6 \mathrm{~mm}$. That is one that effectively merges the two curves in Figure 13 meaning a model for interfacial friction factor that holds irrespective of pipe diameter. The correlation procedure involves the introduction of a factor $\left(\frac{t}{D} F r_{g}\right)^{-1.1}$ which is a dimensionless group comprising the gas phase Froude number characterising the gravitational wave velocity of the gas-liquid interface and the film thickness non-dimensionlised by pipe diameter $t / D$. The index $(-1.1)$ is obtained by regression analysis to produce the best fit. Both $t / D$ and $F r_{g}$ are functions of the pipe diameter, thereby making the dimensionless group $\left(\frac{t}{D} F r_{g}\right)^{-1.1}$ an even stronger function of pipe diameter. This new group remarkably collapsed all the data producing a reasonably good fit (see Figure 14). We have also added the data of Chung \& Mills (1974) thus showing that these data are fairly consistent with the current results. The slight under-prediction of Chung \& Mills (1974) data can be attributed to the 
fact that for their work, the film thickness was not measured directly but was calculated by a relation developed by Brotz (1954), however, the consistency with our data is noted.
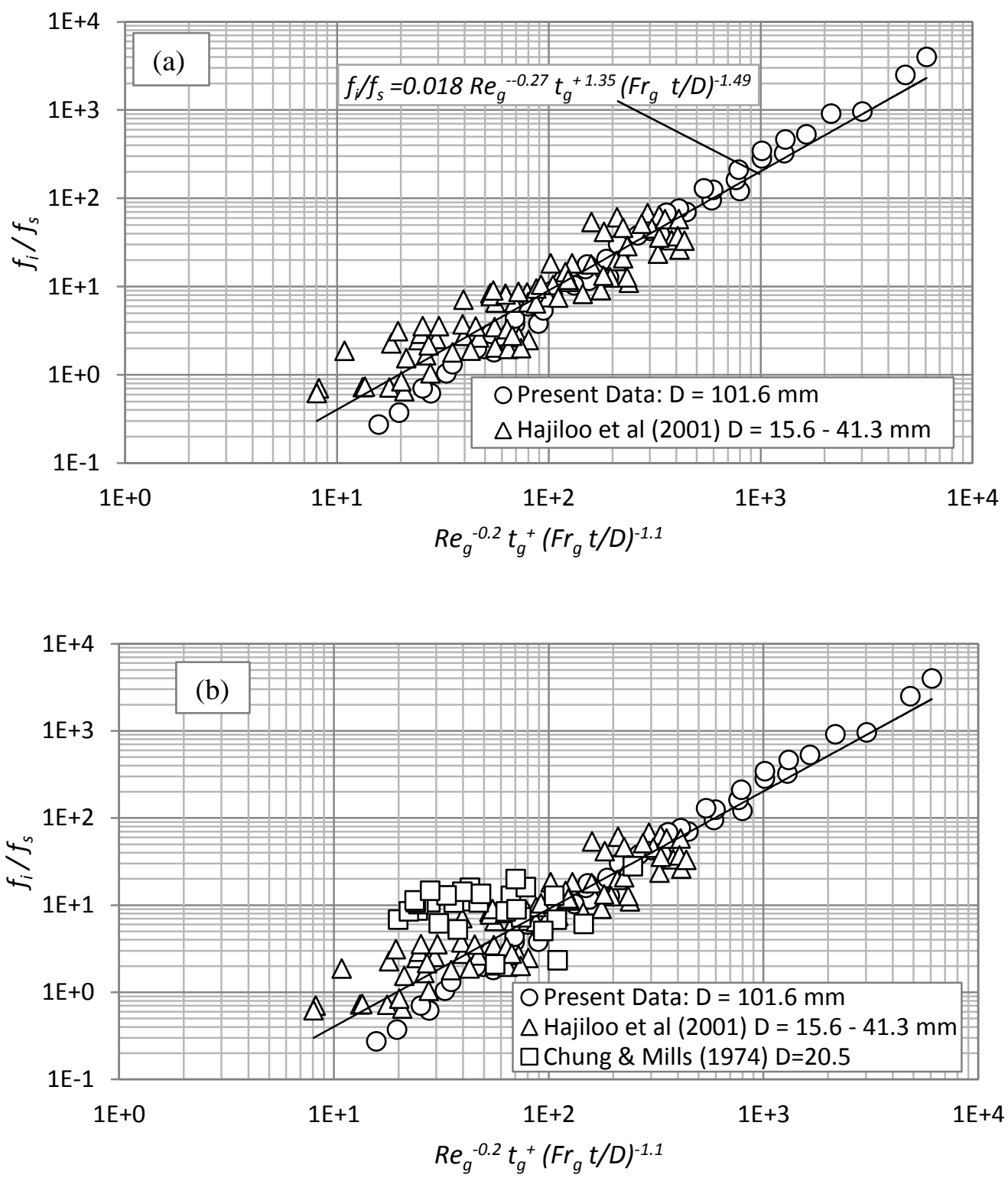

Figure 14: (a) Empirical correlation for downward interfacial friction factor covering both large and small diameter pipes. (b) Test of correlation using the data of Chung \& Mills (1974)

Our resulting correlation is as follows

$$
\frac{f_{i}}{f_{S}}=0.018 R e_{g}^{-0.27} t_{g}^{+1.35}\left(F r_{g} \frac{t}{D}\right)^{-1.49}
$$

Where $F r_{g}$ the gas Froude number calculated as

$$
F r_{g}=\frac{u_{s g}}{\sqrt{g D}}
$$


In the application of Equation (32) situations may arise where $t / D$ is not readily available from measured data and may have to be estimated by correlation. The film thickness correlation of Almabrok et al. (2015) can be used

$$
t^{*}=t\left(g / v_{l}^{2}\right)^{1 / 3}=1.4459 R e_{l f}^{0.3051}
$$

Figure 15(b) shows that using Almabrok et al's $t / D$ correlation produces more scatter than if experimental film thicknesses are used (Figure 15(a)); it nevertheless predicts $f_{i} / f_{s}$ with $56.3 \%$ of all data points within $\pm 50 \%$ of our experimental $f_{i} / f_{s}$.

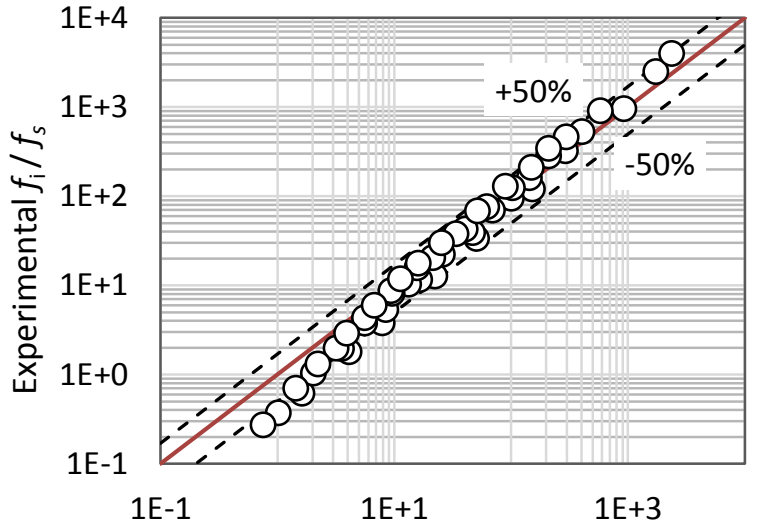

(a) Calculated $f_{i} / f_{s}$ (With experimental t/D)

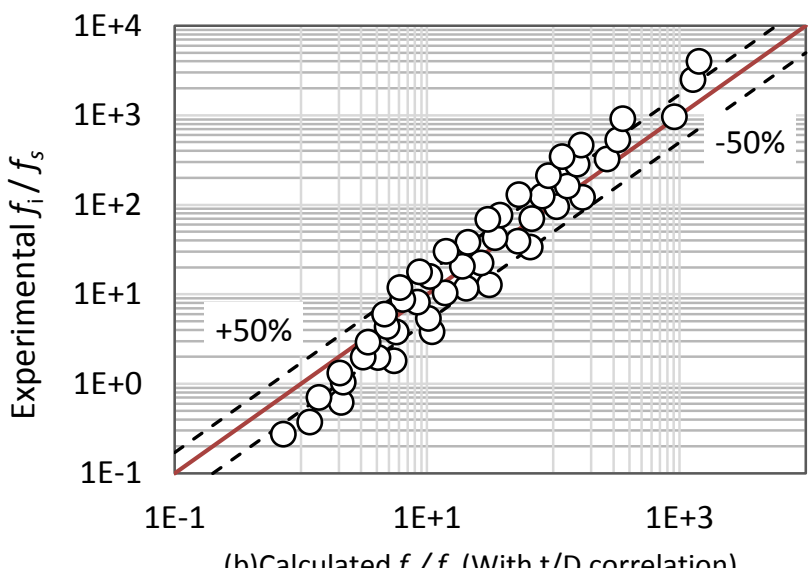

(b)Calculated $f_{i} / f_{s}$ (With t/D correlation)

Figure 15: Interfacial friction factor calculations: using measured experimental film thickness data from $101.6 \mathrm{~mm}$ ID pipe vs that predicted with Equation (32)

All data for $101.6 \mathrm{~mm}$ ID pipes obtained for this work fell within $\pm 96.7 \%$ of Equation (32), our developed correlation. In fact, $85.42 \%$ of all data points (large and small) fell within $\pm 50 \%$ of this equation, thereby outperforming the other models surveyed (Table 3). Hajiloo et al.'s (2001) model was the best performer among the previously published correlations in terms of predicting our large diameter data with $39.58 \%$ of its predictions within $50 \%$ of our data and all of its predictions within $100 \%$ together with having the lowest percentage mean absolute error. The other models all produced predictions above $100 \%$ mean absolute error with Fukano et al. recording over $700 \%$ as is seen in Figure 9 with predictions exhibiting large scatter. In the case of our model correlated for both large and small pipes Equation (32), the mean absolute error is slightly higher than that for large pipes only large pipes (Equation (30)). This could be as a result of uncertainty introduced by Hajiloo et al's film thicknesses which were predicted rather than measured. In any case, Equation (32) outperforms all the previously published correlations and can be used more conveinently irrespective of pipe diameter, but produces slightly less accuracy when compared to the correlations of Hajiloo et al for small pipes and our Equation (30) for larger pipes respectively. 
Table 3: Statistical comparison between large diameter experimental data and correlations

\begin{tabular}{|c|c|c|c|c|c|c|c|}
\hline \multirow[b]{2}{*}{ Performance parameter } & \multirow[b]{2}{*}{$\begin{array}{c}\text { Henstock \& } \\
\text { Hanratty } \\
\text { (1976) }\end{array}$} & \multirow[b]{2}{*}{$\begin{array}{l}\text { Asali et } \\
\text { al.(1985) }\end{array}$} & \multirow[b]{2}{*}{$\begin{array}{l}\text { Fukano et } \\
\text { al. (1991) }\end{array}$} & \multirow[b]{2}{*}{$\begin{array}{l}\text { Hajiloo et } \\
\text { al. (2001) }\end{array}$} & \multicolumn{3}{|c|}{ Present work } \\
\hline & & & & & $\begin{array}{l}\text { Equation } \\
\quad(30)\end{array}$ & $\begin{array}{l}\text { Equation } \\
\text { (32) }\end{array}$ & $\begin{array}{l}\text { Equation } \\
(32)^{\dagger}\end{array}$ \\
\hline $\begin{array}{l}\text { \% Mean Absolute } \\
\text { Error* }\end{array}$ & 295.91 & 135.19 & 700.45 & 56.5 & 31.69 & 42.49 & 63.93 \\
\hline$\%$ within $\pm 50 \%$ of data & 20.83 & 18.75 & 14.58 & 39.58 & 85.42 & 75 & 56.25 \\
\hline$\%$ within $\pm 100 \%$ of data & 64.58 & 81.25 & 33.33 & 100 & 100 & 87.5 & 83.33 \\
\hline
\end{tabular}

Despite the improved predictions of our developed correlation, it is worth mentioning that it must be applied with great caution outside $R e_{l}$ and $R e_{g}$ ranges of 11300-113000 and 3756-187000 respectively from which the correlation were developed. Figure 16 is a flowchart that summarises the model development procedure utilised in this paper.

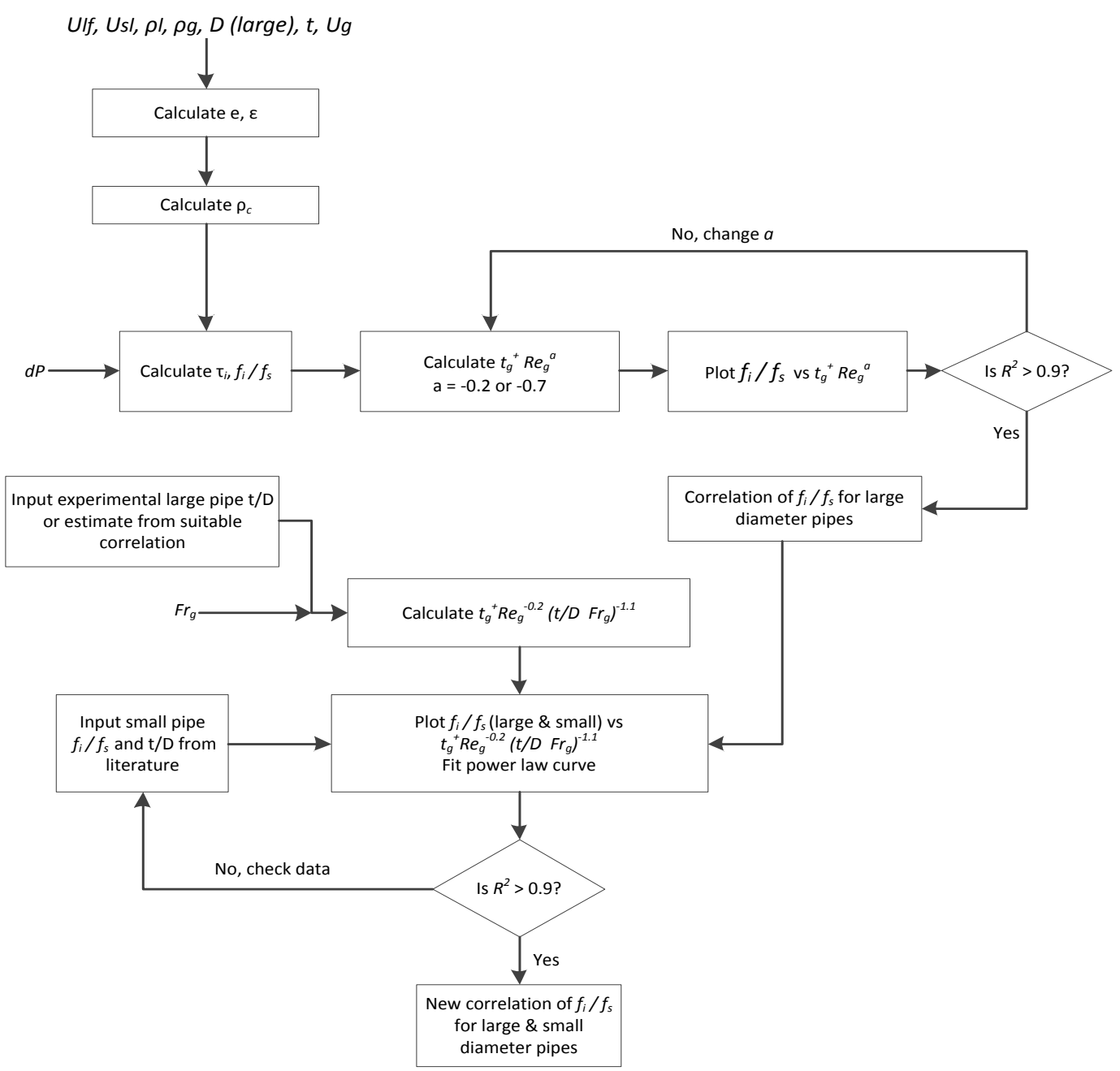

Figure 16: Flowchart for model development procedure 


\section{Concluding remarks}

Several investigators have published studies showing that in turbulent multiphase flow systems, using correlations obtained from small diameter pipe systems to predict the behaviour of larger pipelines leaves much to be desired. An important class of such correlations are those predicting friction losses for the determination of pressure drops. Unfortunately, published large diameter friction flow data is scarce for developing new correlations, particularly for downward two-phase flow. In this paper, we report new experimental data for interfacial friction factor obtained in a co-current air-water downward large diameter flow loop. The main findings are summarized as follows:

1. Pipe scale effect is important in determining interfacial shear in annular flow a shown when the experimental data in this experiment was compared with existing correlations

2. It was found out that the interfacial friction factor in downwards annular flow is a function of $R e_{g}^{-0.2} t_{g}^{+}\left(F r_{g} \frac{t}{D}\right)^{-1.1}$ for large diameter pipes rather than $R e_{g}^{-0.2} t_{g}^{+}$as established by earlier researchers for smaller tubes. The former group was shown to also well correlate small diameter pipe interfacial friction factor.

3. Data on downflow interfacial friction factor obtained from other authors in the open literature were found to be consistent with the developed correlation.

\section{Acknowledgement}

Aliyu M Aliyu would like to express sincere gratitude to the Nigerian Government for the scholarship funding his $\mathrm{PhD}$ through the Petroleum Technology Development Fund's Overseas Scholarship Scheme (PTDF/E/OSS/PHD/AMA/622/12).

\section{Nomenclature}

\section{A. Symbols}

\begin{tabular}{|cll|}
\hline Symbol & Units & Description \\
$A_{d}, A_{g}, A_{l f}$ & {$\left[\mathrm{~m}^{2}\right]$} & Droplet, gas, and liquid film cross-sectional area \\
$D$ & {$[\mathrm{~m}]$} & Pipe internal diameter \\
$e$ & {$[-]$} & Entrained liquid fraction \\
$F$ & {$[-]$} & Modified Martinelli flow parameter \\
$F r_{g}, F r_{l}$ & {$[-]$} & Gas Froude, Liquid Froude number \\
$f_{i}$ & {$[-]$} & Interfacial friction factor \\
$f_{s}$ & {$[-]$} & Single phase friction factor \\
$\mathrm{g}$ & {$\left[\mathrm{m} / \mathrm{s}^{2}\right]$} & Acceleration due to gravity \\
$L$ & {$[\mathrm{~m}]$} & Pipe length \\
$P$ & {$[\mathrm{~Pa}]$} & Local pressure \\
$\Delta P$ & {$[\mathrm{~Pa}]$} & Differential pressure \\
& & \\
$-\frac{d P}{d z}$ & {$[\mathrm{~Pa} / \mathrm{m}]$} & Pressure gradient \\
$R e_{g}$ & {$[-]$} & Gas Reynolds number \\
$R e_{l f}$ & {$[-]$} & Liquid film Reynolds number \\
$R e_{l}$ & {$[-]$} & Liquid Reynolds number \\
$t$ & {$[\mathrm{~m}]$} & Film thickness \\
& & Dimensionless film thickness defined as a frictional \\
\hline
\end{tabular}


B. Greek Letters

\begin{tabular}{|c|c|c|}
\hline$t^{+}$ & {$[-]$} & $\begin{array}{l}\text { distance parameter: } t_{g}^{+}=t / \nu_{g} \sqrt{ } \tau_{i} / \rho_{g} \\
\text { Nusselt's dimensionless film thickness defined as: } \\
t^{*}=t\left(g / v_{l}^{2}\right)^{1 / 3}\end{array}$ \\
\hline$u^{*}$ & {$[-]$} & Friction velocity: $u^{*}=\sqrt{\tau_{i} / \rho_{g}}$ \\
\hline$u_{l f}$ & {$[\mathrm{~m} / \mathrm{s}]$} & Liquid film velocity \\
\hline$u_{s g}, u_{s l}$ & {$[\mathrm{~m} / \mathrm{s}]$} & Superficial gas, liquid velocity \\
\hline$W_{E}, W_{l f}, W_{t}$ & {$[\mathrm{~kg} / \mathrm{s}]$} & $\begin{array}{l}\text { Entrained droplet, liquid film and total liquid mass flow } \\
\text { rate }\end{array}$ \\
\hline$W e_{c}$ & {$[-]$} & Core flow Weber number \\
\hline$W e$ & {$[-]$} & Weber number \\
\hline$x$ & {$[-]$} & Gas quality \\
\hline$X$ & {$[-]$} & Martinelli parameter \\
\hline $\mathrm{z}$ & [m] & Axial distance along pipe \\
\hline
\end{tabular}

\begin{tabular}{|cll|}
\hline Symbol & Units & Description \\
$\varepsilon$ & {$[-]$} & Void fraction \\
$\varepsilon_{c}$ & {$[-]$} & Gas core void fraction \\
$\gamma$ & {$[-]$} & Liquid droplet hold up \\
$v_{l}, v_{g}$ & $\mathrm{~m}^{2} / \mathrm{s}$ & Gas, liquid kinematic viscosity \\
$\mu_{c}, \mu_{g}, \mu_{l}$ & {$[\mathrm{~kg} / \mathrm{s}-\mathrm{m}]$} & Core, gas, liquid dynamic viscosity \\
$\rho_{c^{\prime}}, \rho_{g}, \rho_{l}$ & {$\left[\mathrm{~kg} / \mathrm{m}^{3}\right]$} & Gas, gas, liquid dynamic density \\
$\sigma$ & {$[\mathrm{N} / \mathrm{m}]$} & Liquid surface tension \\
$\tau_{i}, \tau_{w}$ & {$[\mathrm{~Pa}]$} & Wall, and interfacial shear stress \\
$\tau_{c}$ & {$[\mathrm{~Pa}]$} & Characteristic shear stress: $\tau_{c}=\frac{2}{3} \tau_{w}+\frac{1}{3} \tau_{i}$ \\
& Unit depends on & Error in quantity indicated \\
$\xi$ & quantity in & in bracket \\
\hline
\end{tabular}

\section{Appendix: Error Analysis}

The uncertainty in $\rho_{c}$ in Equation (13) is deduced from its definition given in Equation (7). When Equations (1), (2), (9) and (10) are substituted in Equation (7) and simplified, this yields an expression explicitly in terms of $u_{l f}$ :

$$
\rho_{c}=\rho_{l}-\frac{\varepsilon\left(\rho_{l}-\rho_{g}\right)}{\varepsilon+\left(1-\frac{\rho_{l} u_{l f} A_{l f}}{W_{t}}\right) \frac{\varepsilon}{(1-\varepsilon)} \frac{1-x}{x} \frac{\rho_{g}}{\rho_{l}}}
$$

Now

$$
\delta\left(\rho_{c}\right)=\delta\left(u_{l f}\right) \frac{\partial \rho_{c}}{\partial u_{l f}}
$$

Where $\frac{\partial \rho_{c}}{\partial u_{l f}}$ is obtained by differentiating Equation (A1) and after rearranging, 


\section{References}

Almabrok, A.A., 2014. Gas - Liquid two-phase flow in up and down vertical pipes. $\mathrm{PhD}$ Thesis, Cranfield University.

Almabrok, A.A., Aliyu, A.M., Lao, L. \& Yeung, H., Gas/liquid flow behaviours in a downward section of large diameter vertical serpentine pipe. International Journal of Multiphase Flow. DOI: 10.1016/j.ijmultiphaseflow.2015.09.012

Al-Yarubi, Q., 2010. Phase flow measurements of annular flows. University of Huddersfield.

Al-Yarubi, Q. \& Lucas, G., 2008. Measurement of the Film Thickness, Film Velocity and Entrainment Fraction in a Liquid-Air Annular Flow Using a Conductance Flowmeter. In pp. 6368. Available at: http://eprints.hud.ac.uk/3681/.

Andreussi, P. \& Zanelli, S., 1979. Downward annular mist flow of air water mixtures. In Dubrovnik, Yugoslavia: International Seminar.

Asali, J.C., 1983. Entrainment in vertical gas-liquid annular flows. Univ of Illinois, Urbana.

Asali, J.C., Hanratty, T.J. \& Andreussi, P., 1985. Interfacial drag and film height for vertical annular flow. AIChE Journal, 31(6), pp.895-902. Available at: http://dx.doi.org/10.1002/aic.690310604.

Azzopardi, B.J., Taylor, S. \& Gibbons, D.B., 1982. Annular two phase flow in a large diameter tube, UKAEA Atomic Energy Research Establishment. Available at: http://books.google.co.uk/books?id=zEfIMgEACAAJ.

Bergelin, O.P. et al., 1949. Co-curreint gas liquid flow. II. Flow in vertical tubes. Heat Transfer and Fluid Mechanics Institute, pp.19-28.

Bhagwat, S.M., Mollamahmutoglu, M. \& Ghajar, A.J., 2012. Experimental investigation and performance evaluation of isothermal frictional two phase pressure drop correlations in vertical downward gas-liquid two phase flow. In Proceedings of the ASME 2012 Summer Heat Transfer Conference. Rio Grande, Puerto Rico: ASME, pp. 1-12. Available at:

http://ghajar.ceat.okstate.edu/pub_pdfs/Bhagwat et al_HT2012-58049.pdf.

Brotz, W., 1954. Uber die Vorausberedinung der Absorptions geschwineig von Gayen instromenden flussig kectsschichten. Chem Ing. Tech., 26, pp.470-8.

Charvonia, D.A., 1959. A Study of the Mean Thickness of the Liquid Film and the Characteristics of the Interfacial Surface in Annular, Two-Phase Flow in a Vertical Pipe., DTIC Document.

Chien, S.F. \& Ibele, W., 1964. Pressure drop and liquid film thickness of two-phase annular and annular-mist flows. Journal of Heat Transfer, 86, pp.89-96.

Chung, D.K. \& Mills, A.F., 1974. Effect of interfacial shear on gas absorption into a turbulent falling film with co-current gas flow. Lett. Heat Mass Transfer, 1, pp.43-48. 
Cicchitti, A. et al., 1960. Two-phase cooling experiments - pressure drop, heat transfer and burnout measurements. Energia Nucleare, 7(6), pp.407-25.

Cioncolini, A. \& Thome, J.R., 2012. Entrained liquid fraction prediction in adiabatic and evaporating annular two-phase flow. Nuclear Engineering and Design, 243, pp.200-213. Available at: http://linkinghub.elsevier.com/retrieve/pii/S0029549311009873 [Accessed March 14, 2013].

Cioncolini, A. \& Thome, J.R., 2010. Prediction of the entrained liquid fraction in vertical annular gas-liquid two-phase flow. International Journal of Multiphase Flow, 36(4), pp.293-302. Available at: http://linkinghub.elsevier.com/retrieve/pii/S0301932209001918 [Accessed April $28,2013]$.

Cioncolini, A., Thome, J.R. \& Lombardi, C., 2009a. Algebraic turbulence modeling in adiabatic gasliquid annular two-phase flow. International Journal of Multiphase Flow, 35(6), pp.580-596. Available at: http://linkinghub.elsevier.com/retrieve/pii/S0301932209000202 [Accessed April $28,2013]$.

Cioncolini, A., Thome, J.R. \& Lombardi, C., 2009b. Unified macro-to-microscale method to predict two-phase frictional pressure drops of annular flows. International Journal of Multiphase Flow, 35(12), pp.1138-1148. Available at: http://linkinghub.elsevier.com/retrieve/pii/S030193220900127X [Accessed April 14, 2013].

Dalkilic, a. S., Laohalertdecha, S. \& Wongwises, S., 2008. Two-phase friction factor in vertical downward flow in high mass flux region of refrigerant HFC-134a during condensation. International Communications in Heat and Mass Transfer, 35(9), pp.1147-1152. Available at: http://linkinghub.elsevier.com/retrieve/pii/S0735193308001292 [Accessed January 24, 2014].

Dukler, A.E., Wicks, M. \& Cleveland, R.G., 1962. Pressure drop and hold-up in two-phase flow: Part A comparison of existing correlations; Part B, An approach through similarity analysis. AIChE Journal, 10(1), p.38.

Fedotkin, I.M. et al., 1979. Pressure drop in downtake turbulent film and gas flows. Fluid Mech. Sov. Res., 8, pp.85-90.

Fukano, T. et al., 1991. Interfacial shear stress and holdup in an air - water Annular two-phase flow. In Proceedings of the ASME-JSME Thermal Engineering Joint Conference: Reno, Nevada, March 17-22, 1991. Amer Society of Mechanical, p. 217.

Gill, L.E., Hewitt, G.F. \& Lacey, P.M.C., 1964. Sampling probe studies of the gas core in annular two-phase flow: II, studies of the effect of phase flow rates on phase and velocity distribution. Chemical Engineering Science, 19(665).

Green, H.L., 1950. Problems in the atomisation of liquids. In Symposium on some aspects of fluid flow. Leamington Spa: Institute of Physics, p. 75.

Hajiloo, M., Chang, B.H. \& Mills, A.F., 2001. Interfacial shear in downward two-phase annular cocurrent flow. Int. J. Multiphase Flow, 27, pp.1095-1108.

Henstock, W.H. \& Hanratty, T.J., 1976. The interfacial drag and the height of the wall layer in annular flows. AIChE Journal, 22(6), pp.990-1000. Available at: http://dx.doi.org/10.1002/aic.690220607. 
Hewitt, G.F. \& Hall-Taylor, N.S., 1970. Annular two-phase flow,, Oxford; New York: Pergamon Press.

Isbin, H.S., Moy, J.E. \& Da Cruz, A.J.R., 1957. Two-phase steam - water criticalflow. AIChE Journal, 3(361).

Kaji, R. \& Azzopardi, B.J., 2010. The effect of pipe diameter on the structure of gas/liquid flow in vertical pipes. International Journal of Multiphase Flow, 36(4), pp.303-313. Available at: http://linkinghub.elsevier.com/retrieve/pii/S0301932209001906 [Accessed October 26, 2012].

Kataoka, I. \& Ishii, M., 1987. Drift flux model for large diameter pipe and new correlation for pool void fraction. Int. J. Heat Mass Transfer, 30(9), pp.1927-1939.

Klausner, J.F., Chao, B.T. \& Soo, S.L., 1991. An improved correlation for two-phase frictional pressure drop in boiling and adiabatic downflow in the annular flow regime. , pp.317-328.

Lane, W.R., 1951. Shatter of drops in streams of air. Ind Eng Chem, 43, p.1312.

Lao, L., Xing, L. \& Yeung, H., 2012. Behaviours of elongated bubbles in a large diameter riser. In Multiphase 8. Banff, Canada: BHR Group, pp. 381-392.

Oliemans, R.V.A., Pots, B.F.M. \& Trompe, N., 1986. Modelling of annular dispersed two-phase flow in vertical pipes. International Journal of Multiphase Flow, 12(5), pp.711-732.

Omebere-Iyari, N.K., 2006. The effect of pipe diameter and pressure in vertical two-phase flow. University of Nottingham.

Omebere-Iyari, N.K. \& Azzopardi, B.J., 2007. A Study of Flow Patterns for Gas/Liquid Flow in Small Diameter Tubes. Chemical Engineering Research and Design, 85(2), pp.180-192. Available at: http://linkinghub.elsevier.com/retrieve/pii/S0263876207730356 [Accessed October $31,2012]$.

Peng, D.J. et al., 2010. Flow regime transitions in large diameter pipes. In 7th International Conference on Multiphase Flow. Tampa, FL USA, pp. 1-9.

Sawant, P., Ishii, M. \& Mori, M., 2008. Droplet entrainment correlation in vertical upward co-current annular two-phase flow. Nuclear Engineering and Design, 238(6), pp.1342-1352. Available at: http://linkinghub.elsevier.com/retrieve/pii/S0029549307005304 [Accessed May 20, 2013].

Schlegel, J.P. et al., 2012. Experimental study of two-phase flow structure in large diameter pipes. Experimental Thermal and Fluid Science, 41, pp.12-22. Available at: http://linkinghub.elsevier.com/retrieve/pii/S0894177712000465.

Tishkoff, J.M., Pinchak, A.C. \& Ostrach, S., 1979. Turbulent co-current gas-liquid flow in a tube with and without swirl. J. Fliuids Eng, 101, pp.61-68.

Wallis, G.B, 1969, One Dimensional Two-Phase Flow, New York: McGraw Hill.

Wright, D. \& Laufenbrenner, D., 1975. Course report. Chem. E., p.379. 